\title{
Predação de gado por onças no Pantanal: características, dinâmica e o conflito com fazendeiros
}

\section{Cattle predation by jaguars and pumas in the Pantanal: characteristics, dynamics and the conflict with ranchers}

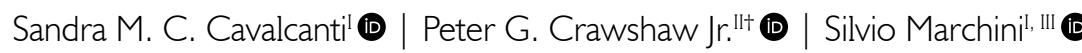 \\ Instituto Pró-Carnívoros. Atibaia, São Paulo, Brasil
}

"Instituto Chico Mendes de Conservação da Biodiversidade/Centro Nacional de Pesquisa e Conservação de Mamíferos Carnívoros.

Atibaia, São Paulo, Brasil (In memorian)

I'Universidade de São Paulo. Piracicaba, São Paulo, Brasil

Resumo: O Pantanal é uma área importante para a conservação da onça-pintada (Panthera onca) e da onça-parda (Puma concolor). No entanto, o bioma possui peculiaridades que tornam a conservação de grandes felinos complexa e desafiadora. A predação do gado gera conflitos entre onças e fazendeiros, que tradicionalmente resultam na eliminação oportunista, porém sistemática, dos predadores. Por outro lado, é crescente entre os fazendeiros o reconhecimento da necessidade de conservar as onças, desde que seja resolvido, ou pelo menos diminuído em níveis toleráveis, o prejuízo que elas causam. Nesse contexto, é importante entender a dinâmica da predação, a fim de identificar ações que possam diminuir efetivamente o seu impacto econômico. Aspectos culturais também têm grande importância, influenciando diretamente na decisão de abater uma onça ou tolerar sua presença. Neste artigo, apresentamos e discutimos as características e a dinâmica da predação de espécies nativas e do gado doméstico por onças no Pantanal, em particular a onça-pintada. Além disso, descrevemos aspectos pessoais, sociais e culturais do conflito, e discutimos suas implicações para a conservação das onças, destacando a importância de entender e envolver os diferentes atores ligados à conservação dessas espécies.

Palavras-chave: Animal-problema. Conflito humano-fauna. Dimensões humanas. Monitoramento animal. Pantaneiro. Panthera onca.

\begin{abstract}
The Pantanal is an important area for the conservation of the jaguar (Panthera onca) and the puma (Puma concolor). However, the biome has peculiarities that make the conservation of jaguars and pumas complex and challenging. Cattle predation generates conflicts between these big cats and ranchers, which traditionally result in the opportunistic yet systematic persecution of the predators. On the other hand, there is a growing recognition among ranchers of the need to conserve jaguars and pumas, as long as the damage they cause is resolved, or at least reduced to tolerable levels. In this context, it is important to understand the dynamics of predation in order to identify actions that can effectively reduce its economic impact. Cultural aspects are also of great importance, directly influencing the decision to slaughter a jaguar or a puma or tolerate its presence. In this article we present and discuss the characteristics and dynamics of predation of native species and domestic cattle by big cats in the Pantanal, in particular the jaguar. In addition, we describe personal, social and cultural aspects of the conflict, and discuss their implications for the conservation of jaguars and pumas, highlighting the importance of understanding and involving the different actors involved in the conservation of these species.
\end{abstract}

Keywords: Problem animal. Human-wildlife conflict. Human dimensions. Wildlife monitoring. Pantaneiro. Panthera onca.

Cavalcanti, S. M. C., Crawshaw Jr., P. G., \& Marchini, S. (2021). Predação de gado por onças no Pantanal: características, dinâmica e o conflito com fazendeiros. Boletim do Museu Paraense Emílio Goeldi. Ciências Naturais, 16(3), 313-334. http://doi.org/10.46357/bcnaturais.v16i3.810 Autora para correspondência: Sandra M. C. Cavalcanti. Avenida Presidente Vargas, 764, Jardim Cerejeiras. Atibaia, SP, Brasil. CEP 12951-000 (cavalcanti1@yahoo.com).

Recebido em dez. 2020

Aprovado em out. 2021

Responsabilidade editorial: Carolina Carvalho Cheida

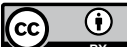




\section{INTRODUÇÃO}

Os grandes predadores têm um importante papel na manutenção da integridade e da biodiversidade dos ecossistemas em que vivem (Noss, 1995; Ray et al., 2005). No entanto, mesmo hoje, alguns países mantêm programas de controle de algumas dessas espécies (Stolzenberg, 2008; Schaller, 2012). Essa situação ocorre, principalmente, devido ao conflito gerado pelos hábitos predatórios dessas espécies, que não apenas competem com o homem por espécies de presas silvestres, na caça de subsistência e desportiva, como também se alimentam de criações domésticas, podendo gerar prejuízos consideráveis em algumas situações (Michalski et al., 2006). Portanto, embora essas espécies sejam consideradas carismáticas para a conservação, são também das mais incompatíveis na convivência com o ser humano (Quammen, 2005). Essa incompatibilidade torna a conservação de grandes carnívoros difícil de justificar perante boa parte da sociedade, mesmo em tempos modernos. Os esforços de conservação são ainda dificultados pelo fato de esses animais requererem grandes áreas de habitat preservado, com uma base estável de presas (Ray et al., 2005). Por esse motivo, áreas protegidas são consideradas como perdidas para a produção de alimentos e outras atividades econômicas, na visão dos segmentos desenvolvimentistas da sociedade. Exemplos atuais no Brasil são as mudanças no Código Florestal Brasileiro e as recentes tentativas de mudanças na lei para permitir mineração nas Unidades de Conservação de proteção integral (Bourscheit, 2013; Bragança, 2013).

Em relação aos maiores carnívoros brasileiros, a onçapintada (Panthera onca) e a onça-parda (Puma concolor), a situação não é diferente (Marchini \& Crawshaw Jr., 2015). Com sua rica e abundante fauna nativa, o Pantanal é considerado uma área importante para a conservação dessas espécies, particularmente para a onça-pintada, que já desapareceu em mais da metade de sua área de distribuição original (Sanderson et al., 2002; De La Torre et al., 2017). Juntamente com a Amazônia, o Pantanal é considerado como um dos últimos refúgios de habitat contínuo para a espécie, embora pouco mais da metade do bioma seja atualmente ocupado por onças-pintadas (Cavalcanti et al., 2012; Camilo, 2012). Não obstante, apesar da sua importância para a conservação desses grandes felinos em longo prazo, o Pantanal possui algumas peculiaridades que tornam as ações para a conservação dessas espécies complexas e desafiadoras. Por mais de 200 anos, centenas de milhares de cabeças de gado têm pastado no mosaico de vegetação da planície pantaneira, em áreas também utilizadas por onças-pintadas, onças-pardas e por suas presas nativas. Dessa forma, o pantaneiro vem coexistindo com os grandes felinos, embora essa coexistência esteja longe de ser pacífica (Crawshaw Jr., 2003; Amâncio et al., 2015; Marchini \& Macdonald, 2012; Cavalcanti et al., 2010, 2012). Devido à proximidade entre o gado e os felinos, aliada ao caráter oportunista desses carnívoros (Cavalcanti \& Gese, 2010), são relativamente comuns eventos de predação, o que contribui para uma visão negativa das onças por parte dos fazendeiros (Schaller, 1983; Sáenz \& Carrillo, 2002; Polisar et al., 2003; Azevedo \& Murray, 2007a).

Apesar desse conflito, quando se consideram as alternativas econômicas possíveis para o Pantanal, a pecuária ainda é a alternativa que mais se alinha com os objetivos da conservação daquele bioma, desde que praticada de forma extensiva, mantendo-se, em grande escala, a vegetação nativa (Crawshaw Jr., 2003; Cavalcanti, 2008). Impactos recentes de outras formas de exploração, principalmente nas bordas da planície pantaneira, envolvendo mineração, agricultura, produção de carvão vegetal e construção de hidrelétricas, têm resultado em ameaças consideráveis ao bioma, com consequências negativas de dimensões ainda desconhecidas (Harris et al., 2005; Crawshaw Jr. et al., 2008; Cavalcanti et al., 2012).

Tradicionalmente, o produtor pantaneiro tem 'resolvido' o problema da depredação de seus rebanhos por meios próprios, através da eliminação oportunista, mas sistemática, de onças-pardas e pintadas. Esse abate é ilegal, sendo muitas vezes realizado de maneira preventiva, antes mesmo que alguns indivíduos tenham causado problemas

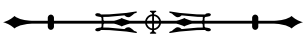


às criações (Hoogesteijn \& Mondolfi, 1992; Crawshaw Jr., 2002). No entanto, existe por parte de alguns fazendeiros uma crescente tendência a entender a necessidade de conservação das onças, desde que seja resolvido, ou pelo menos diminuído para níveis toleráveis, o prejuízo que algumas delas causam (Crawshaw Jr., 2003). Nesse contexto, é importante entender a dinâmica da predação do gado doméstico por predadores no Pantanal e os fatores que contribuem para esse processo (Azevedo \& Murray, 2007a; Cavalcanti \& Gese, 2010), a fim de direcionar ações que possam diminuir efetivamente o seu impacto econômico (Cavalcanti et al., 2012). Além dos aspectos técnicos que levam a entender melhor a predação, devem ser analisados também os aspectos culturais das pessoas envolvidas, que influenciam diretamente a decisão de abater ou não um predador, independente do fator de risco que ele represente para os animais domésticos (Amâncio et al., 2015; Cavalcanti et al., 2010; Marchini \& Macdonald, 2012).

O presente artigo apresenta e discute informações sobre as características e a dinâmica da predação de espécies nativas e do gado doméstico por grandes felinos no Pantanal, em particular a onça-pintada, para ilustrar como se dá o conflito com produtores, do ponto de vista econômico. As informações são baseadas nos resultados de um estudo de longo prazo realizado no bioma entre 2000 e 2005 (Cavalcanti \& Gese, 2010; Cavalcanti et al., 2010), e complementadas por dados disponíveis na literatura. Em seguida, o artigo descreve os aspectos pessoais, sociais e culturais do conflito, discute suas implicações para a conservação das onças e destaca a importância de entender e envolver os diferentes atores ligados à conservação dessa espécie. À conclusão, são apresentadas sugestões de alternativas preventivas e mitigatórias em relação ao conflito entre os grandes predadores e a atividade pecuária no Pantanal.

\section{CONSIDERAÇÕES SOBRE MONITORAMENTO ANIMAL}

Para possibilitar a coleta de informações detalhadas sobre a dieta da onça-pintada no sul do Pantanal, Cavalcanti
\& Gese (2010) usaram um sistema acurado e intensivo de monitoramento dos animais aparelhados, através de radiotelemetria, com sistema integrado de posicionamento global (GPS). Os colares GPS utilizados no estudo (Televilt/ Followit, Suécia) foram programados para registrar 12 localizações por dia para cada indivíduo monitorado (uma localização a cada duas horas). Cada vez que uma onça permanecia por um tempo prolongado em um mesmo local, formando uma concentração de pontos, o mesmo era checado, na tentativa de localizar a carcaça de uma possível presa. Esses aglomerados de localizações eram sistematicamente investigados em períodos entre um e 21 dias (para descrição completa dos métodos, ver Cavalcanti \& Gese, 2010).

O grande número de localizações obtidas para cada um dos dez indivíduos aparelhados (de 512 a 3.932 localizações por indivíduo, $n=11.787$ ) permitiu não apenas o monitoramento de grandes áreas, mas também a obtenção de informações contínuas sobre os movimentos desses animais, independentemente de condições climáticas, hora do dia (ou da noite) ou estação do ano. Essas informações possibilitaram detectar, com alto nível de precisão (erro < $10 \mathrm{~m}$ ), uma amostragem significativa de eventos de predação $(n=415)$, com 438 presas documentadas. Essas informações sobre padrões e taxas de predação adotados por diferentes indivíduos revelam aspectos ecológicos importantes do comportamento da espécie, incluindo o seu papel como predador do gado no Pantanal (Cavalcanti \& Gese, 2010).

\section{CARACTERIZAÇÃO DA PREDAÇÃO}

Para contextualizar o problema, pode-se considerar que a depredação de animais domésticos geralmente começa por uma situação particular que leva um predador a cruzar a linha do desconhecido, em que ele ataca um animal até então não considerado como uma presa para ele, isto é, que não faz parte das presas em potencial no aprendizado pelo qual passou com a sua mãe - no caso de a mãe nunca ter predado animais domésticos.

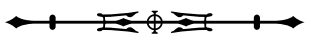


Sendo os grandes felinos predadores oportunistas (Schaller, 1983; Cavalcanti \& Gese, 2010), eles geralmente respondem a estímulos desencadeados por uma situação específica, resultando comumente de um encontro em que um animal reage fugindo, o que estimula o comportamento de perseguição no predador (Møller \& Erritzøe, 2014). Se o animal é alcançado, os processos de contenção e abate são simultâneos e instintivos, principalmente em felinos (Ewer, 1968, 1973; Kitchener, 1991) (Figura 1). Se, nesse momento, a esse turbilhão de reações instintivas estiver também associada a fome, ele será induzido ao consumo do animal abatido. Uma vez consumado esse processo, em que o predador obteve sucesso, conseguindo se alimentar, o evento é registrado no seu repertório comportamental, sendo repetido toda vez que a oportunidade se apresentar novamente. No caso de esse indivíduo ser uma fêmea, ela poderá repassar esse comportamento aos filhotes que irá gerar durante sua vida reprodutiva (Ewer, 1973). Sob o ponto de vista evolutivo-adaptativo, essa possibilidade permite uma flexibilidade comportamental, que permite ao animal (e a seus descendentes) adaptar-se a condições que mudem em seu ambiente, principalmente em um mundo rapidamente alterado pelo ser humano (Logan \& Sweanor, 2001).

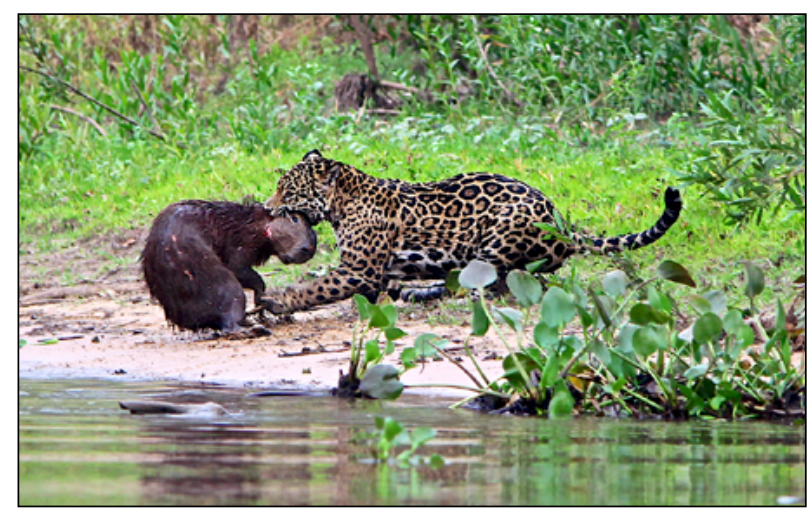

Figura 1. Capivara (Hydrochoerus hydrochaeris) sendo predada por uma onça-pintada na margem do rio Cuiabá, na região de Poconé, MS. Foto: R. Boulhosa (2010).

Figure 1. Capybara (Hydrochoerus hydrochaeris) being predated upon by a jaguar on the margins of the Cuiabá river, in Poconé, MS. Photo: R. Boulhosa (2010).
Uma análise do banco de dados de predação do Centro Nacional de Pesquisa para Conservação de Mamíferos Carnívoros/Instituto Chico Mendes de Conservação da Biodiversidade (CENAP/ICMBio) indica que $98 \%$ de todos os casos de conflitos causados por mamíferos carnívoros no Pantanal envolvem a onça-pintada e a onça-parda (Cavalcanti, 2010). No entanto, o Pantanal é uma região singular no Brasil quanto ao problema de predação por onças. Na maior parte da região, os problemas relacionados à depredação de rebanhos domésticos não estão relacionados à perda de habitat. Mais de $95 \%$ do Pantanal são compreendidos por propriedades privadas com grandes extensões, onde a criação de gado constitui a principal atividade econômica (Abreu et al., 2008). No entanto, em uma porção significativa do bioma, a pecuária é explorada de forma extensiva e utiliza pastagens naturais que mantêm os habitats, em grande parte, em sua forma original (Specht et al., 2012). Da mesma forma, a predação de rebanhos domésticos também não está relacionada à baixa densidade de presas nativas (Schaller, 1983; Rodrigues et al., 2002; Desbiez et al., 2010). A caça praticada pelo homem pantaneiro é tradicionalmente direcionada a poucas espécies, em especial ao porco-monteiro (Sus scrofa), espécie exótica que representa 91\% da preferência de caça na região (Desbiez et al., 2011; Lourival \& Fonseca, 1997; Mourão et al., 2002). Desta forma, a competição do ser humano com predadores carnívoros pelas presas naturais dos mesmos é relativamente baixa no Pantanal (Jorgenson \& Redford, 1993).

\section{ESPÉCIES NATIVAS COMO COMPONENTES DA DIETA}

Embora a onça-pintada consiga subjugar mesmo as presas de maior porte no Pantanal, vários estudos comprovam a natureza oportunista da espécie, em termos da diversidade de presas que compõe a sua dieta (Schaller, 1983; Crawshaw Jr. \& Quigley, 2002; Azevedo \& Murray, 2007a; Dalponte, 2002; Polisar et al., 2003; Scognamillo et al., 2002; Perilli et al., 2016; Porfírio, 2009; Cavalcanti, 2008). De fato, considerando-se toda a área de distribuição da espécie,

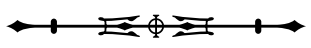


mais de 85 espécies de presas já foram mencionadas como integrantes da sua dieta (Sunquist \& Sunquist, 1989).

No estudo de Cavalcanti \& Gese (2010), mais da metade (68\%) dos animais abatidos pelas onças monitoradas ( $n=438$ ) era de espécies da fauna nativa. No entanto, os indivíduos estudados apresentaram diferenças na diversidade de espécies presente em suas dietas. Embora coletivamente as onças-pintadas tenham consumido 24 espécies diferentes de presas, alguns indivíduos se restringiram a poucas espécies, enquanto outros foram mais generalistas. A Figura 2, embora não represente todas as espécies abatidas durante o estudo, ilustra essa diferença individual por parte dos predadores.
Uma vez que os dados de Cavalcanti \& Gese (2010) se basearam na frequência de animais abatidos e taxas de predação, comparações diretas com estudos baseados na análise de fezes podem não ser apropriadas. No entanto, se a análise for feita sobre a ocorrência de presas nas fezes, independente da sua quantidade, a comparação é possível. Estudos da dieta de onças-pintadas realizados através de análise de fezes em Miranda (Perilli, 2010, n = 160; Porfírio, 2009, $n=134$ ) corroboraram os resultados de Cavalcanti \& Gese (2010). Os autores identificaram 23 (Perilli, 2010) e 20 (Porfírio, 2009) diferentes táxons a partir de itens alimentares presentes nas fezes. Da mesma forma, Azevedo \& Murray (2007b) registraram 19 diferentes

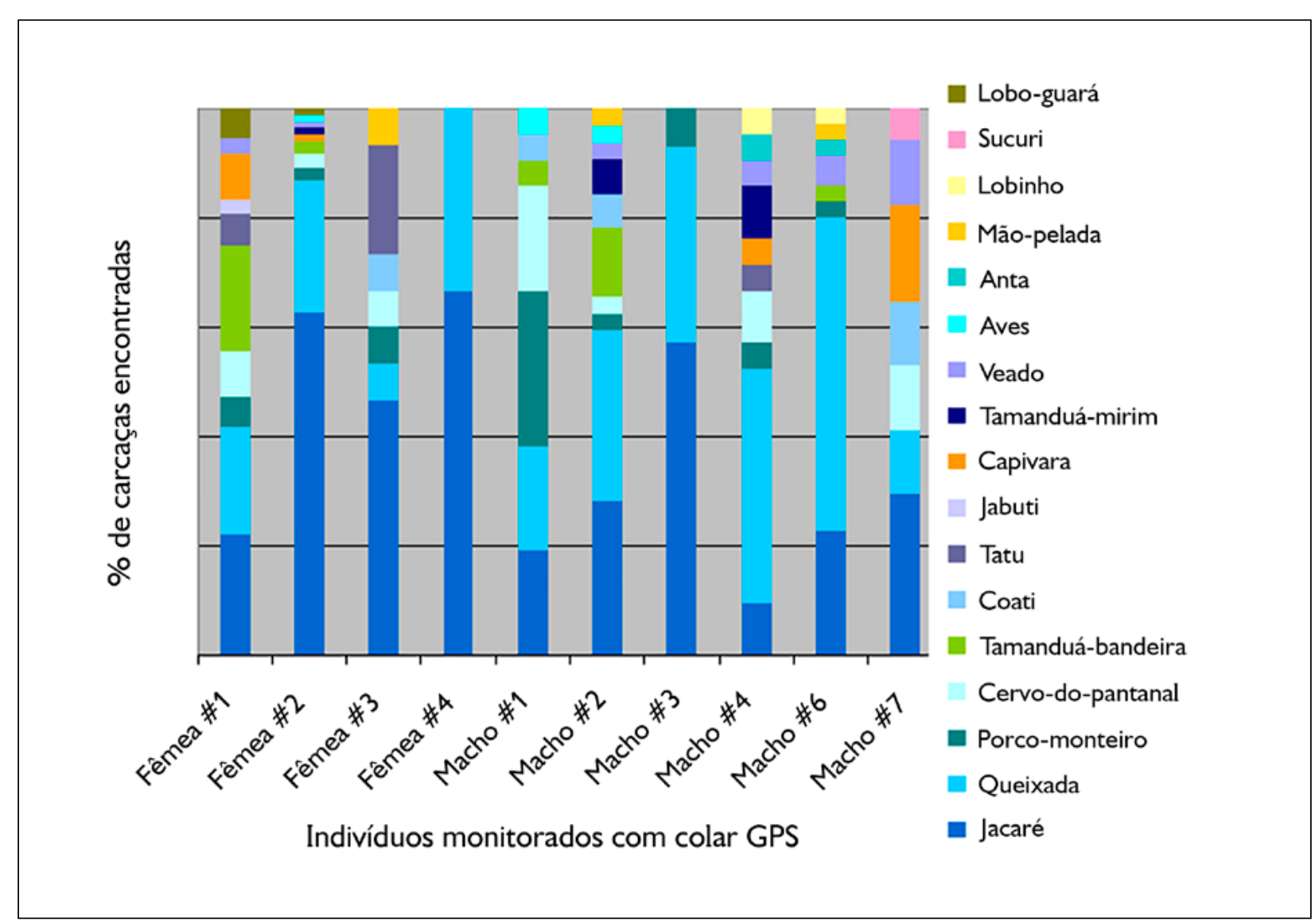

Figura 2. Espécies nativas mortas por dez onças-pintadas monitoradas com colares GPS em uma fazenda de pecuária na região de Miranda, Mato Grosso do Sul, entre novembro de 2001 e abril de 2004. Fonte: Cavalcanti (2008).

Figure 2. Native species killed by ten jaguars monitored with GPS collars on a ranch in the region of Miranda, Mato Grosso do Sul, between November 2001 and April 2004. Source: Cavalcanti (2008).

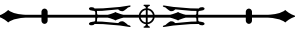


táxons através da análise de fezes $(n=149)$ de onças pardas e de onças-pintadas, coletadas em outra área de estudo, também na região de Miranda.

Embora grande parte dos táxons de presas registrados no estudo de Cavalcanti \& Gese (2010, Figura 2) tenha ocorrido em baixa frequência, eles ilustram a plasticidade nos hábitos alimentares da onçapintada e confirmam sua natureza oportunista. Essas presas apresentam uma variedade de características e particularidades que influenciam a predação por parte das onças monitoradas. Essas particularidades podem variar, por exemplo, em relação ao valor calórico da presa ou ao tempo que as mesmas ficam vulneráveis, como seu comportamento de forrageamento. Outra característica importante é o grau de atratividade da presa, considerando a palatabilidade em relação aos mecanismos de defesa. Um cervo-do-pantanal (Blastocerus dichotomus), por exemplo, pode apresentar peso e valor calórico similar a um bezerro entre três e cinco meses de idade (Duarte, 1996; Catto et al., 2005); porém, comparativamente, seus mecanismos de defesa o tornam uma presa menos atrativa.

É interessante ressaltar a presença de quatro espécies de carnívoros entre os animais predados (lobo-guará, Chrysocyon brachyurus, $\mathrm{n}=3$; lobinho, Cerdocyon thous, $\mathrm{n}=3$; coati, Nasua nasua, $\mathrm{n}=5$; mão-pelada, Procyon cancrivorus, $n=3$; Figura 2). Tanto quanto se pôde apurar a partir de cada uma dessas carcaças, todos eles foram mortos e consumidos como presas normais, e não para evitar competição.

Os dados da Figura 2 mostram que o número de espécies abatidas pode variar muito entre indivíduos, indicando uma seleção diferenciada de presas. Além das características inerentes a cada uma das espécies de presa, essa diferença na seleção por parte das onças é também, possivelmente, devido a: (1) disponibilidade ou vulnerabilidade sazonal entre as espécies; (2) diferenças no processo de aprendizado individual por parte das onças e/ ou nos efeitos desse processo na formação da imagem de busca (search image; Ricklefs \& Miller, 2000) de diferentes presas em determinado momento ou estação do ano; ou (3) preferências individuais das onças estudadas, além de uma possível interação entre esses fatores.

\section{O GADO COMO COMPONENTE DA DIETA}

Um ponto recorrente e importante no aspecto alimentar da onça-pintada é o seu papel como predador do gado e o quanto ela é, de fato, responsável por prejuízos econômicos para a pecuária pantaneira. A importância do gado na dieta da onça-pintada pode variar consideravelmente entre diferentes áreas no Pantanal. Em duas áreas ao norte do Pantanal (Jofre e Paraguaizinho), na região de Poconé, Dalponte (2002) indicou que o gado constituiu a base da dieta de onçaspintadas, representando $43 \%$ dos itens encontrados nas fezes analisadas ( $n=28$ ). Em contraste, Porfírio (2009), também através de análise de fezes, citou uma porcentagem de ocorrência muito menor para o gado (17,6\%) em uma área na região de Miranda, ao sul do Pantanal.

Não obstante, a importância do gado na dieta das onças pode variar também em uma mesma região. Através da análise direta das carcaças de animais mortos em uma fazenda na região de Miranda, Cavalcanti \& Gese (2010) indicaram que o gado representou cerca de um terço $(n=139,32 \%)$ do total de presas abatidas $(n=438)$ pelas onças. Em uma fazenda vizinha, Crawshaw Jr. \& Quigley (2002) observaram que o gado foi o principal item alimentar na dieta das onças, perfazendo quase metade $(47,5 \%)$ do total de animais abatidos por onças-pintadas ( $n$ $=59$ ) e onças pardas (41,9\%, $n=31)$. De acordo com os autores, essa alta porcentagem de gado na dieta das onças não é surpreendente, considerando-se que essa espécie representava a maior biomassa de alimento disponível para esses predadores à época do estudo (início da década de 80), com cerca de 70.000 cabeças na área da fazenda (248.000 ha). Usando-se a estimativa de $175 \mathrm{~kg}$ como peso médio por cabeça (Schaller, 1983), esses dados resultam em uma biomassa de $4.900 \mathrm{~kg} / \mathrm{km}^{2}$ apenas para o gado. No entanto, os autores chamam a atenção para o fato de seus dados terem sido compostos, em grande parte,

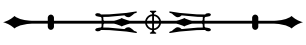


por carcaças encontradas por peões da fazenda, os quais são geralmente mais propensos a encontrar carcaças de gado do que de animais silvestres. Adicionalmente, algumas espécies da fauna nativa são menores, sendo possivelmente mortas e consumidas em áreas afastadas, o que as torna mais difíceis de serem encontradas (Crawshaw Jr. \& Quigley, 1984). Desta forma, é de se esperar que essas espécies estejam subrepresentadas e, consequentemente, que a importância do gado seja superestimada em amostragens realizadas de forma oportunista. Quando Crawshaw Jr. \& Quigley $(1984,2002)$ examinaram 17 carcaças de animais abatidos encontrados usando apenas as localizações de onças equipadas com rádio-colar, observaram que $29 \%$ das carcaças foram representadas por gado e $41 \%$ por queixadas. Embora nesse estudo o gado tenha representado uma parte significativa da dieta tanto de onças-pardas quanto de onçaspintadas, os níveis de predação variaram entre essas duas espécies em relação às diferentes classes de tamanho e idade do gado. Os autores observaram que bezerros (com até dois anos de idade) constituíram cerca de um terço (32\%) do total do gado abatido por onças-pintadas $(n=28)$. Vacas constituíram mais da metade da amostra (57\%), sendo que bois e touros representaram 7\% e 4\%, respectivamente. Com relação às carcaças de animais predados por onçaspardas, a espécie praticamente se restringiu a bezerros, uma vez que os mesmos representaram $92 \%$ do total de carcaças por elas abatidas ( $n=13)$. Os autores notaram que a única vaca morta por onça-parda tinha pouco mais de dois anos de idade, tendo sido predada por um indivíduo macho e adulto.

No estudo de Cavalcanti \& Gese (2010), bezerros (com até um ano de idade) representaram a maioria (69\%) do total do gado abatido por onças-pintadas $(n=139)$. De uma forma geral, esses resultados são semelhantes aos de outros estudos. Na Venezuela, os ataques por onça-pintada ao gado foram direcionados a animais jovens (bezerros machos e fêmeas, garrotes e novilhas com menos de dois anos) com maior frequência do que animais adultos (Hoogesteijn et al., 1993; Farrell, 1999; Scognamillo et al., 2002). No noroeste da Argentina, a maioria dos ataques a rebanhos domésticos foi direcionada ao gado entre um e três anos de idade (Perovic, 2002).

\section{PRESAS PREFERENCIAIS}

Os jacarés (Caiman crocodilus yacare), os queixadas (Tayassu pecari) e o gado representaram a grande maioria (77\%) de todas as carcaças examinadas ( $n=438$ ) por Cavalcanti \& Gese (2010), formando a base da dieta da onçapintada na área de estudo. Os resultados de uma análise independente de fezes (Perilli et al., 2016), conduzida na mesma área, confirmaram essas mesmas espécies (gado - 33,3\%, queixadas - 18,2\% e jacarés - 17,7\%) como as mais abatidas pelas onças-pintadas na região. $\bigcirc$ fato de as fezes utilizadas nessa análise terem sido coletadas na mesma área dos animais monitorados por Cavalcanti \& Gese (2010), durante o mesmo período de estudo, não necessariamente implica o fato de elas corresponderem a esses mesmos indivíduos. A extensa sobreposição das áreas de vida dos animais estudados (Cavalcanti \& Gese, 2009)e os registros fotográficos de 29 indivíduos adicionais na área (Soisalo \& Cavalcanti, 2006) dão suporte a esta asserção.

Os resultados de Azevedo \& Murray (2007a) indicaram que capivaras (31\%, $n=35)$ e jacarés (20\%, $n=23)$ foram as presas nativas mais importantes, mas que o gado representou $28 \%(n=32)$ de todas as carcaças encontradas $(n=114)$. Em contraste, os autores não registraram consumo frequente de queixadas, que representaram apenas 0,9\% das carcaças encontradas. Além dessas três espécies principais (capivara, gado e jacaré), os cervos-do-pantanal representaram outros 10\% das carcaças encontradas (Azevedo \& Murray, 2007b). A diversidade de habitats, tão característica do Pantanal, justifica essa disparidade no consumo de queixadas e capivaras entre os dois estudos. De acordo com Desbiez et al. (2010), as comunidades de mamíferos variam de acordo com a paisagem. A fazenda onde Azevedo \& Murray (2007b) desenvolveram seu estudo é caracterizada, além de possuir áreas com mata semidecidual e campos naturais, por ter extensas áreas com culturas de arroz em escala comercial. Essas áreas atraem espécies de presas nativas, como capivaras

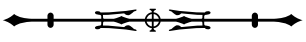


e cervos-do-pantanal (de Paula \& Silva Neto, 2006), sendo estas as presas mais consumidas pelas onças-pintadas.

Vale chamar a atenção para um ponto importante, na comparação temporal entre os estudos de Crawshaw Jr. \& Quigley (1984) e Cavalcanti \& Gese (2010). À época em que os primeiros autores desenvolveram o projeto, entre 1980 e 1984, sua área de estudo, uma fazenda de pecuária no município de Miranda, Mato Grosso do Sul, no sul do Pantanal, abrangia 248.000 ha. Imediatamente após esse período, a fazenda foi desmembrada entre diferentes proprietários, sendo que a área onde Cavalcanti e Gese trabalharam, entre 2000 e 2005, era uma das fazendas remanescentes, com 46.000 ha, que abrangia a porção oeste da área original do primeiro estudo. Portanto, é de se esperar que os resultados dos dois estudos apresentem similaridades. Por outro lado, há uma diferença marcante em relação à predação em jacarés, que durante o primeiro estudo nunca foi documentada, apesar de ter sido feita uma amostragem relativamente grande dos hábitos alimentares das onças-pintadas à época ( $n=$ 61), mas este foi um dos itens mais comuns registrados no segundo estudo. Crawshaw Jr. \& Quigley (1984) citaram, ainda, Almeida (1976), que relatou a predação de jacarés como sendo comum no norte do Pantanal, na região de Cáceres, e estranharam o fato de essa preferência não ter sido constatada para a sua área de estudo. No município de Poconé, Dalponte (2002) citou a capivara, juntamente com o gado, como a principal fonte de alimentação para as onças-pintadas no norte do Pantanal, representando $63 \%$ da dieta das mesmas. O autor cita jacarés como uma presa importante, mas consumida em menor proporção.

\section{FREQUÊNCIA DE ATAQUES}

Além da composição da dieta das onças-pintadas estudada por Cavalcanti \& Gese (2010), em termos da proporção das diferentes espécies presentes, o grande número de carcaças encontradas (entre 18 e 124 presas abatidas por onça estudada) permitiu que fosse estimada a frequência individual de ataques, aqui expressa pelo número de dias entre o abate de presas consecutivas por cada animal. A frequência média de predação para todas as espécies de presa foi de cinco dias entre ataques por onça. As frequências de ataques variaram entre os diferentes indivíduos estudados, com a onça-pintada mais velha (macho \#1) apresentando a menor frequência (sete dias entre ataques). Em contraste, um macho subadulto (macho \#6) apresentou a maior frequência de ataques entre as onças-pintadas estudadas (3,6 dias entre ataques), embora o mesmo estivesse acompanhado de sua mãe e de sua irmã no período em que foi monitorado.

Uma vez que o gado, os jacarés e os queixadas representaram a base da dieta das onças-pintadas (77\% de todas as carcaças encontradas), Cavalcanti \& Gese (2010) analisaram separadamente as frequências de ataques para cada uma dessas espécies ao longo do estudo, para identificar se houve variação sazonal nessas frequências entre os anos de 2001 a 2004. A frequência de ataques sobre os queixadas aumentou de maneira significativa ao longo dos anos, enquanto que a frequência de ataques ao gado diminuiu (Figura 3). Esse aumento significativo na frequência de ataques de queixadas sugere crescimento na importância da espécie na dieta das onças-pintadas na área de estudo. Tal resultado foi também observado através da análise sazonal de fezes ( $n=160)$ na mesma área (Perilli et al., 2016). O aumento na importância de queixadas na dieta de onças-pintadas tem implicações importantes não apenas na dinâmica do sistema predador-presa no Pantanal, mas também influi no conflito gerado pela depredação do gado, uma vez que o aumento na predação de queixadas coincidiu com diminuição na predação do gado (Figura 3).

Como anteriormente mencionado, um fator importante, que certamente influi na predação, é o tamanho da presa. Como seria de se esperar, o tempo decorrido entre eventos subsequentes de predação por um mesmo animal varia conforme o tamanho da espécie predada (Cavalcanti \& Gese, 2010). De acordo com os autores, indivíduos que predam presas grandes ( $>45 \mathrm{~kg}$ ) 


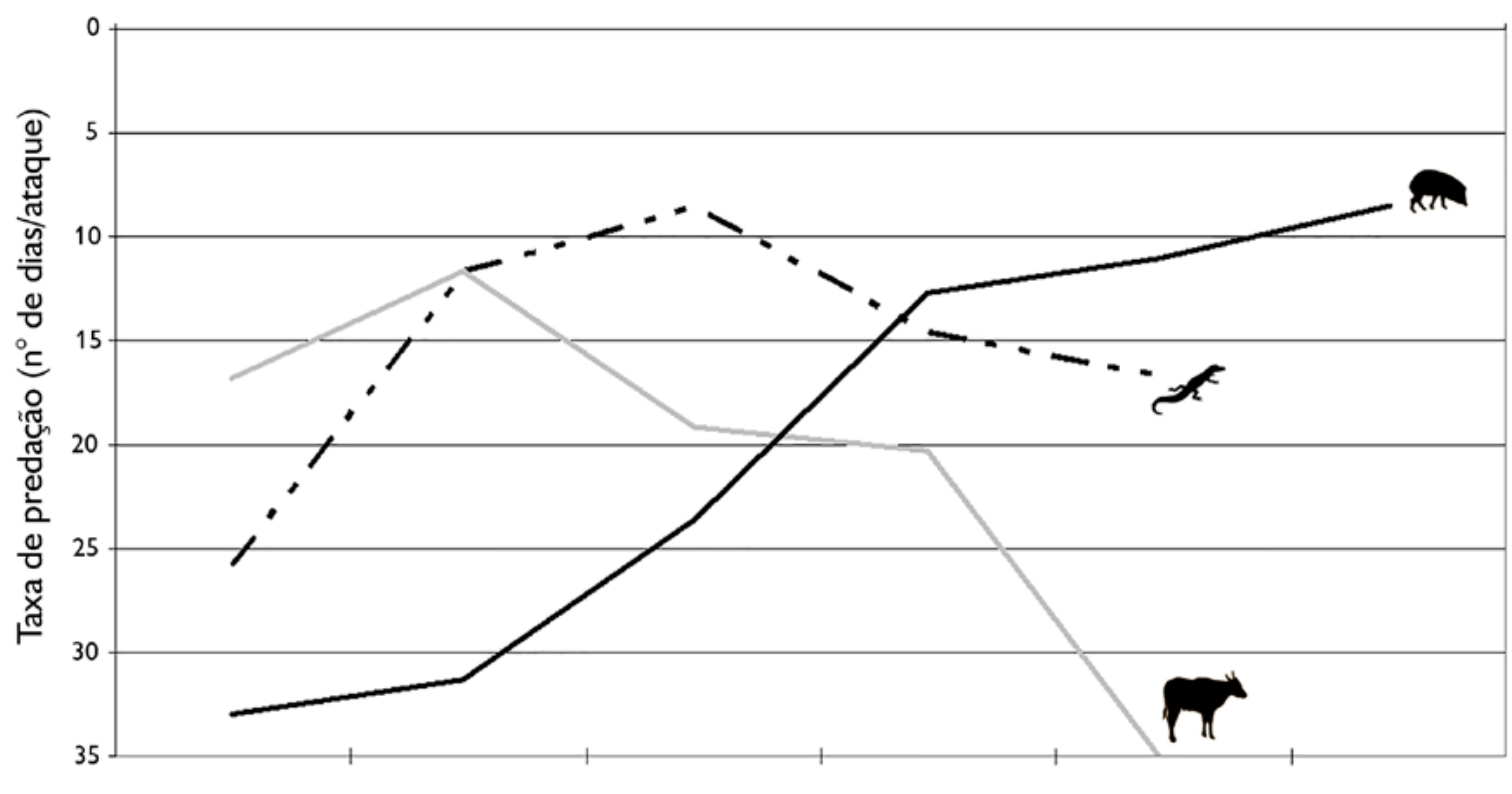

Cheia 2001-2002 Seca 2002 Cheia 2002-2003 Seca 2003 Cheia 2003-2004 Seca 2004

Figura 3. Variação sazonal nas taxas de predação de jacarés, queixadas e gado por onças-pintadas monitoradas com colares GPS em uma fazenda de pecuária na região de Miranda, Mato Grosso do Sul, entre novembro de 2001 e abril de 2004. Fonte: Cavalcanti (2008).

Figure 3. Seasonal variation in the predation rates of caimans, peccaries and cattle by jaguars monitored with GPS collars on a livestock farm in the region of Miranda, Mato Grosso do Sul, between November 2001 and April 2004. Source: Cavalcanti (2008).

em maior proporção apresentam geralmente menores frequências de ataques. Por outro lado, após consumir uma espécie de presa de menor porte $(<45 \mathrm{~kg})$, a onçapintada geralmente ataca novamente outra presa em um intervalo de tempo mais curto.

Da mesma forma, o tempo que uma onça-pintada permanece se alimentando de uma presa também varia de acordo com o tamanho da mesma. Quanto maior a presa, mais tempo o predador permanece junto à carcaça, o que sugere um consumo maior do animal abatido. Devido ao clima quente e úmido do Pantanal, as carcaças se deterioram rapidamente, o que torna difícil documentar a quantidade consumida por cada onça, para cada carcaça encontrada (Figura 4). No entanto, os autores levantam a hipótese de que a permanência do predador junto à carcaça de sua presa esteja diretamente relacionada às atividades de guarda e consumo da mesma.

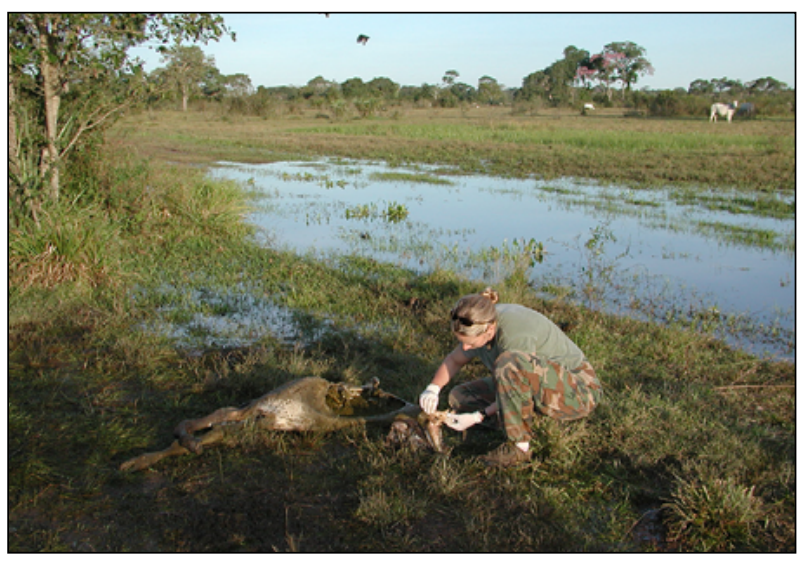

Figura 4. A autora checando em campo a carcaça de uma rês abatida por uma onça-pintada, fazenda Sete, município de Aquidauana, MS. A rapidez com que as carcaças se deterioram devido ao clima quente e úmido, inviabiliza o registro da quantidade exata de presa consumida por cada onça. Foto: Eric Gese (2005).

Figure 4. The author checking the carcass of a domestic calf killed by a jaguar, Sete ranch, municipality of Aquidauana, MS. Due to the hot and humid climate, it is very dificult to determine the portion of the carcass consumed by each jaguar. Photo: Eric Gese (2005).

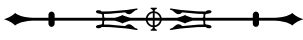


SAZONALIDADE DA PREDAÇÃO E ALTERNÂNCIA ENTRE ESPÉCIES DE PRESA

Para testar se a variação climática influi na seleção de presas e, dessa forma, poder determinar se as onças alternam sazonalmente entre diferentes espécies, Cavalcanti \& Gese (2010) examinaram o número de carcaças encontradas predadas em cada estação do ano. Das 299 carcaças de todas as espécies nativas encontradas, 43,5\% $(n=130)$ foram encontradas na estação de cheia e 56,5\% ( $\mathrm{n}=$ 169), na estação seca. Para o gado ( $n=139)$, no entanto, a maioria $(68 \%, n=94)$ foi encontrada durante a estação seca. Quando os autores examinaram separadamente o número médio mensal ou a frequência de abates (abates de presa/mês) das três principais espécies predadas, i.e., gado, jacarés e queixadas, ao longo de toda a duração do estudo, identificaram um padrão sazonal de predação.
A predação de gado mostrou um pico nas estações secas, embora seja aparente uma diferença entre os anos de 2002 e 2003 (Figura 5).

Ainda que a predação em jacarés tenha sido igualmente distribuída ao longo do ano de 2002, os resultados mostram que em 2003 e 2004 ocorreram picos durante a estação da cheia. Esses picos coincidiram com a diminuição na predação do gado. Com relação aos queixadas, embora a distribuição das carcaças encontradas indique uma predação distribuída igualmente ao longo de 2002, é aparente um aumento significativo em 2003 e 2004. Os dados de Perilli e colegas (2016) corroboram esses resultados. De acordo com os autores, a análise de fezes $(n=160)$ sugere picos de predação ao gado nas estações secas e aumento gradativo na predação de queixadas durante o estudo.

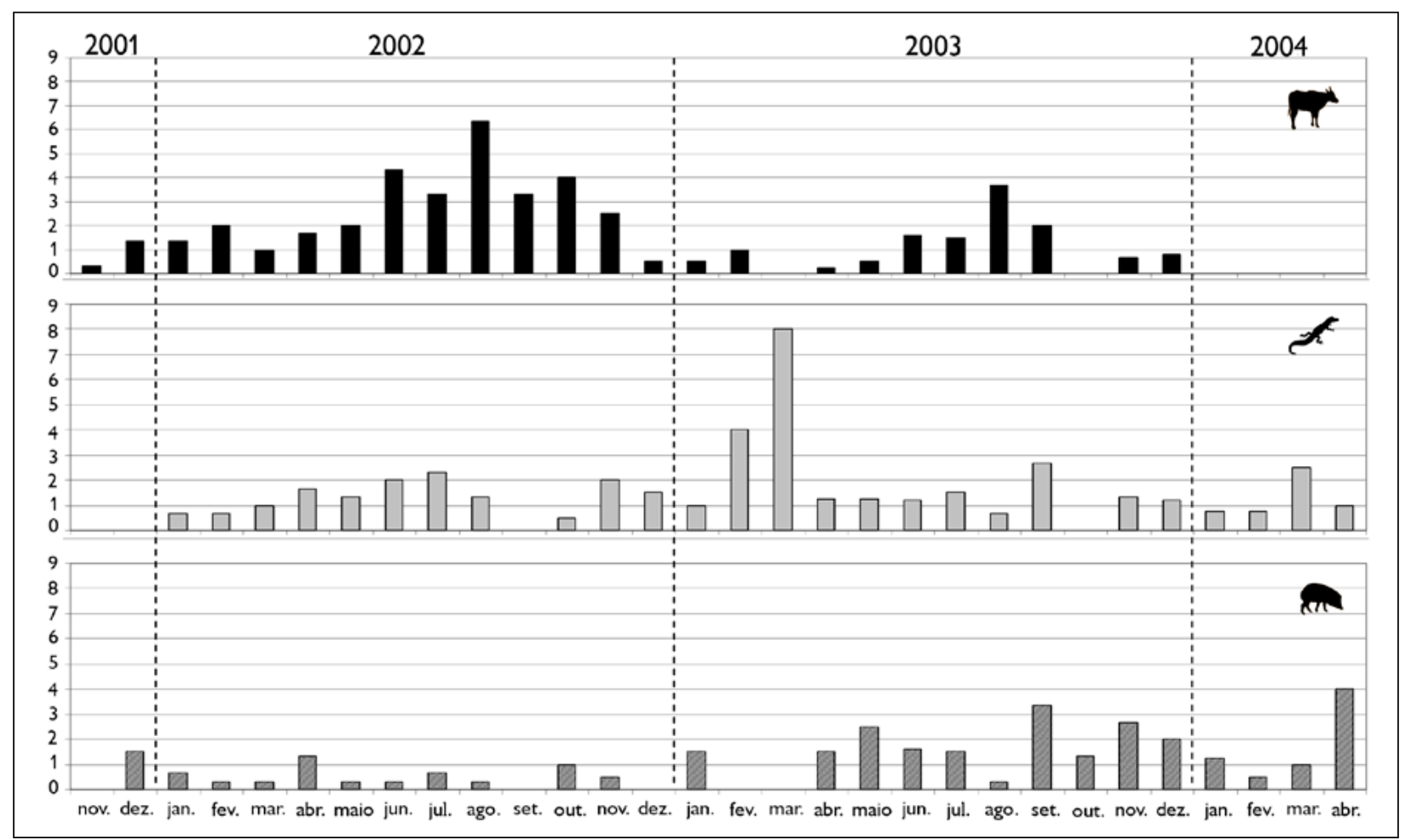

Figura 5. Distribuição do número médio de cabeças de gado, jacarés e queixadas mortos por mês por onças-pintadas monitoradas com colares GPS em uma fazenda de pecuária na região de Miranda, Mato Grosso do Sul, entre novembro de 2001 e abril de 2004. Fonte: Cavalcanti (2008).

Figure 5. Distribution of the average number of cattle, caimans and white-lipped peccaries killed per month by jaguars monitored with GPS collars on a ranch in the region of Miranda, Mato Grosso do Sul, between November 2001 and April 2004. Source: Cavalcanti (2008).

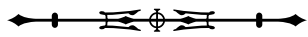




\section{HORÁRIOSDASINCIDÊNCIASDE PREDAÇÃO E TIPO DE AMBIENTE ONDE OCORRE}

Predadores como a onça-parda e a onça-pintada são frequentemente considerados crepusculares ou mesmo noturnos (Crawshaw Jr. et al., 2004; Nowak, 1999; Nowell \& Jackson, 1996; Hoogesteijn et al., 1993). No entanto, os resultados do estudo de Cavalcanti \& Gese (2010) indicam que o horário dos ataques documentados em relação a todas as espécies de presas, incluindo o gado, se mostrou bem distribuído no período de $24 \mathrm{~h}$ (Figura 6). Os dados mostram, portanto, que a onçapintada não seleciona horários específicos para atacar o gado, mas o faz de maneira oportunista, de noite ou de dia, caracterizando uma flexibilidade comportamental da espécie (Cavalcanti \& Gese, 2010). Essa característica, de fato, já seria de se esperar, considerando que o mosaico vegetacional do Pantanal (Prance \& Schaller, 1982) proporciona cobertura suficiente para que o predador possa se aproximar de sua presa sem ser detectado (Stander, 1990).

Ademais, análises espaciais das ocorrências de predação em relação ao tipo de vegetação (Cavalcanti \& Gese, 2010; Cavalcanti, 2008) sugerem que, no Pantanal,

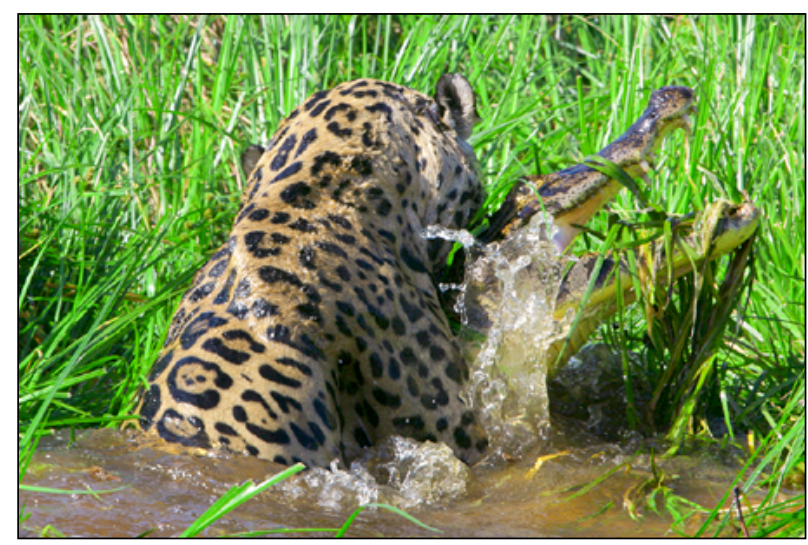

Figura 6. Onça-pintada predando um jacaré (Caiman crocodilus yacare) em plena luz do dia, na mergem do rio Cuiabá, na região de Poconé, MS. Foto: R. Boulhosa (2012).

Figure 6. Jaguar killing a caiman (Caiman crocodilus yacare) in broad daylight, on the margins of the Cuiabá river, in Poconé, MS. Photo: $R$. Boulhosa (2012). outros habitats além de florestas são igualmente importantes na procura de presas por parte das onças. Vários autores sugerem manter os rebanhos afastados de áreas de florestas como uma estratégia para minimizar ataques (Rabinowitz, 1986; Quigley, 1987; Hoogesteijn et al., 1993; Michalski et al., 2006). Embora em outras regiões essa estratégia possa ser adequada, dados coletados em diferentes áreas do Pantanal (Cavalcanti, 2008, 2009) indicam que a onçapintada ataca o gado também em outros habitats, além de florestas. Os animais monitorados no estudo não evidenciaram uma seleção por áreas de mata para atacar o gado, como também o predaram em áreas de campo sujo, em campo com árvores esparsas e mesmo em áreas de campo aberto (Cavalcanti, 2008) (Figura 7). Além disso, manter os rebanhos fora de áreas florestadas é uma estratégia inviável, dentro da realidade do Pantanal, onde invernadas e pastagens geralmente abrangem diversos fragmentos de mata, ou capões, como são localmente conhecidos.

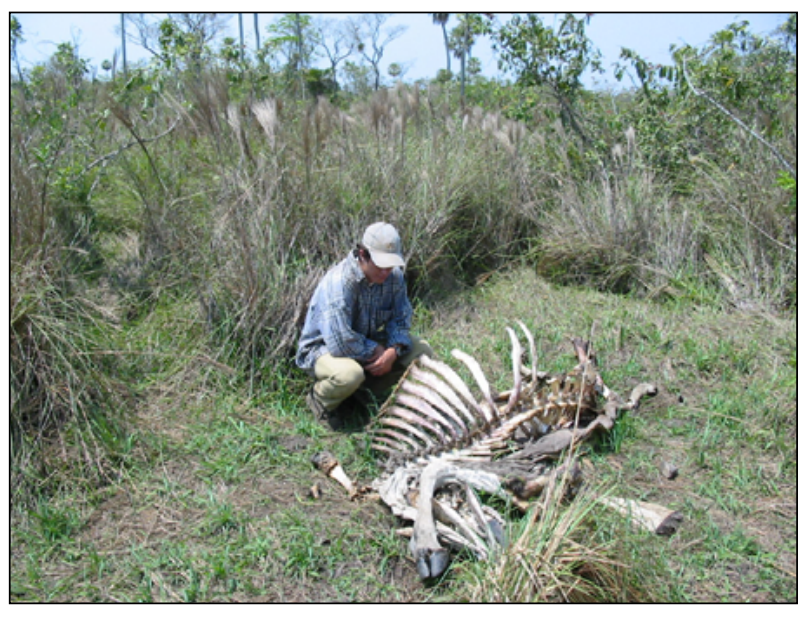

Figura 7. No pantanal, onças-pintadas, oportunistas que são, matam suas presas em outros habitats, além de florestas. Na fazenda Sete, município de Aquidauana, MS, os pesquisadores encontraram essa carcaça no meio de um campo sujo. Foto: Sandra Cavalcanti (2006).

Figure 7. In the pantanal, jaguars kill cattle in habitats other than forests. In Sete ranch, in the municipality of Aquidauana, MS, researchers found this carcass in the middle of an open field with brushy vegetation. Photo: Sandra Cavalcanti (2006).

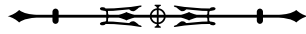




\section{O CONCEITO DE ANIMAIS-PROBLEMA}

De acordo com Roosevelt (1914), nem todas as onças atacam o gado. Segundo esse autor, a depredação por onças-pintadas no Brasil prevalece em áreas com escassez de presas nativas, mas é infrequente em áreas com alta disponibilidade de presas. Embora essa situação possa ocorrer em alguns locais e, de fato, tenha sido descrita por Azevedo e Murray (2007b) para uma fazenda no município de Miranda, essa noção de causa e efeito não serve como modelo para o Pantanal. No estudo de Cavalcanti \& Gese (2010), mesmo em áreas com fauna silvestre abundante, todos os indivíduos monitorados eventualmente predaram o gado (Figura 8). No entanto, a proporção entre espécies nativas e o gado variou significativamente entre os diferentes indivíduos estudados. Se para alguns indivíduos mais da metade das presas consistiram em gado doméstico, para outros, essa proporção não ultrapassou 5\% (Figura 9).

Essa diferença individual nos ataques ao gado desperta a questão sobre 'animais-problema' (Linnell et al., 1999). A crença no fato de que a eliminação ou remoção de um 'animal-problema' resolva a questão

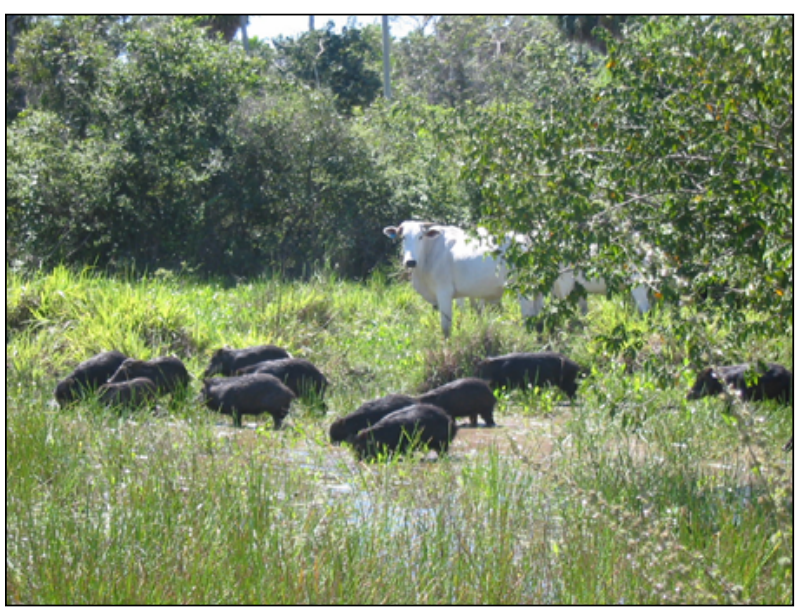

Figura 8. Em um estudo na fazenda Sete, município de Aquidauana, MS, todas as onças-pintadas monitoradas predaram o gado doméstico, apesar da presença de fauna silvestre abundante. Foto: Sandra Cavalcanti.

Figure 8. In a study in Sete ranch, in the municipality of Aquidauana, MS, all monitored jaguars killed domestic cattle, despite an abundance of native prey. Photo: Sandra Cavalcanti. da depredação (Almeida, 1976; Rabinowitz, 1986; Hoogesteijn \& Mondolfi, 1992) não é, necessariamente, aplicável ao Pantanal. Estudos sugerem que a maioria dos predadores que atacam animais domésticos é formada por indivíduos debilitados ou de alguma forma incapacitados de caçar normalmente (Rabinowitz, 1986; Fox \& Chundawat, 1988; Hoogesteijn et al., 1993). Em duas áreas na Venezuela, a maioria das onças-pintadas (75\% e 53\%) mortas como medida de controle da depredação havia sofrido ferimentos debilitantes prévios (Hoogesteijn et al., 1993). Da mesma forma, uma fêmea e um macho nos Parques Nacionais do Iguaçu (Brasil) e Iguazu (Argentina), respectivamente, ambos com mais de dez anos de idade estimada e com caninos quebrados, tiveram que ser removidos por estarem predando predominantemente animais domésticos (Crawshaw Jr. et al., 2004). No entanto, em dois estudos diferentes no Pantanal, todos os animais monitorados se apresentaram em excelentes condições físicas quando capturados para colocação de colares (Schaller \& Crawshaw Jr., 1980; Cavalcanti \& Gese, 2010). Os últimos autores citaram um dos seus animais de estudo (macho \#1), já velho e debilitado, mas que aparentemente não teve problemas para matar presas nativas potencialmente perigosas, como queixada, porcomonteiro e cervo-do-pantanal.

Os dados de 2002 sugerem que as condições climáticas podem influenciar na seleção de presas pela onça-pintada de maneira mais significativa do que a preferência individual ou a 'propensão' para atacar o gado, e a prática de alternar entre diferentes espécies de presa é um comportamento comum entre os predadores (Cavalcanti \& Gese, 2010). Esse estudo foi desenvolvido durante um período com condições climáticas extremas, que abrangeu anos extremamente secos e outros úmidos, e a maioria dos ataques ao gado ocorreu no ano de 2002, quando a estiagem se prolongou por um período além do normal (Cavalcanti \& Gese, 2010; Desbiez et al., 2010). De acordo com os autores, a proporção de gado (todas as faixas etárias combinadas) entre as carcaças de animais

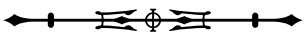




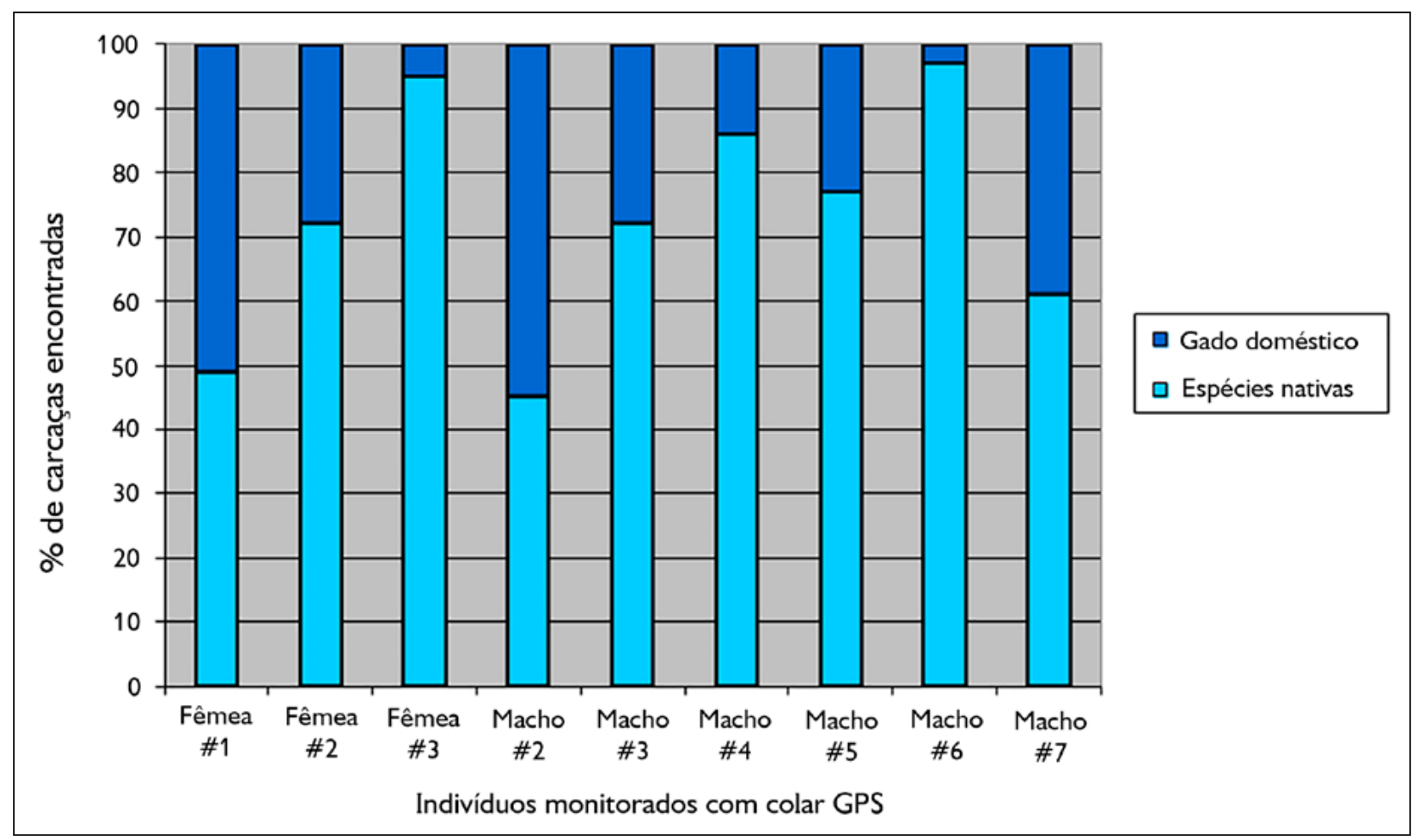

Figura 9. Distribuição de presas nativas e gado doméstico morto por onças-pintadas monitoradas com colares GPS em uma fazenda de pecuária na região de Miranda, Mato Grosso do Sul, entre novembro de 2001 e abril de 2004. Fonte: Cavalcanti (2008).

Figure 9. Distribution of native prey and domestic cattle killed by jaguars monitored with GPS collars on a ranch in the Miranda region, Mato Grosso do Sul, between November 2001 and April 2004. Source: Cavalcanti (2008).

abatidos diminuiu de 49\%, em 2002 (ano mais seco), para 19\%, em 2003 (ano mais úmido).

Rabinowitz (1986) sugeriu que, uma vez que uma onça-pintada preda o gado, esse indivíduo passa a tratar a espécie como sua principal presa. Em Miranda, uma fêmea cuja dieta em 2002 consistia em > 50\% de gado, incluindo vacas adultas, parou completamente de atacar o gado em 2003, quando as condições climáticas ficaram favoráveis, predando apenas espécies nativas (Cavalcanti, 2008).

Embora a crença popular atribua à onça-pintada o hábito de se alimentar exclusivamente de presas abatidas por ela, diversos estudos confirmam que esse carnívoro se alimenta com frequência de animais mortos por outras causas (Lopez-Gonzales \& Piña, 2002; Crawshaw Jr. \& Quigley, 2002; Cavalcanti \& Gese, 2010). Nesse sentido, é importante também esclarecer o papel dessa espécie como necrófaga. Ao final da estação seca, no Pantanal, é comum encontrar gado já debilitado pela falta de pasto adequado, atolado em poças ou açudes que estão secando. Já sem forças, esses animais demoram, às vezes, até três ou mais dias para morrer, muitas vezes tendo os olhos arrancados por aves necrófagas (urubus, Coragyps atratus, Sarcorhamphus papa, Cathartes sp. e caracarás, Polyborus plancus) (Figura 10). Quando onças encontram gado nessas condições, é frequente elas abaterem esses animais e se alimentarem das carcaças (Schaller, 1983). Esse é um exemplo de aproveitamento de recursos disponíveis e que integra a ecologia local, por dar acesso à carcaça também para outros consumidores da cadeia alimentar.

Embora a onça-pintada possa atacar e matar touros adultos (Crawshaw Jr. \& Quigley, 2002; Hoogesteijn et al., 1993), Cavalcanti \& Gese (2010) não documentaram 


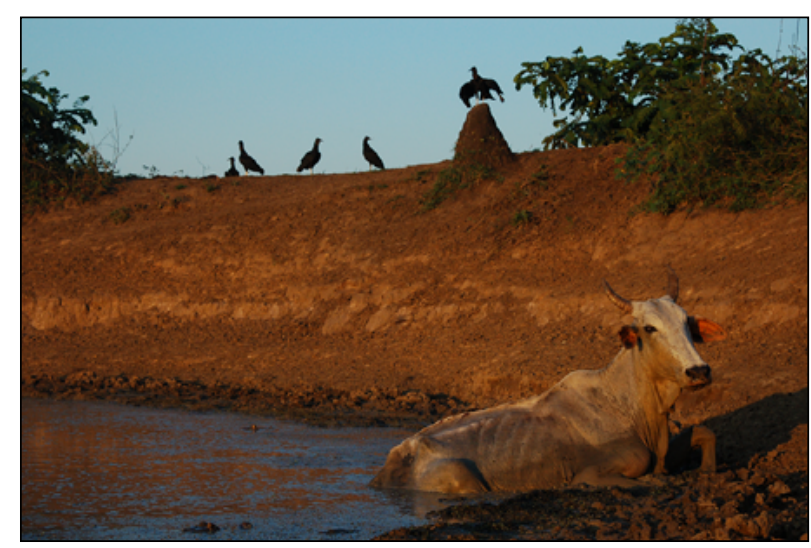

Figura 10. Rês atolada em poça remanescente, ao final da estação seca no Pantanal, fazenda Sete, município de Aquidauana, Mato Grosso do Sul, em 03/10/2004. Foto: Sandra Cavalcanti (2002).

Figure 10. Calf stuck in a remaining pool, at the end of the dry season in the Pantanal, Sete ranch, municipality of Aquidauana, Mato Grosso do Sul, on 10/03/2004. Photo: Sandra Cavalcanti (2002).

nenhum caso envolvendo essa classe entre as 139 carcaças de gado predadas por essa espécie. No entanto, esses autores documentaram seis casos em que as onças-pintadas monitoradas se alimentaram de carcaças de bovinos mortos por outras causas, incluindo a de um touro adulto. Um caso similar ocorreu também no Pantanal de Poconé, onde um touro que havia sido atropelado por um caminhão na rodovia Transpantaneira, em terras da fazenda Jofre, foi comido por um macho de onça-pintada, em 1979. Nessa ocasião, o predador permaneceu junto à carcaça por pelo menos três dias, como faria se o animal tivesse sido morto por ele. Para qualquer pessoa que não soubesse do atropelamento, o evento teria sido interpretado como predação.

Esse papel da onça-pintada como necrófaga é importante no cenário de conflito entre proprietários e predadores, uma vez que pode interferir no diagnóstico da causa de mortalidade, se o mesmo for conduzido por pessoas sem a devida experiência ou sem o conhecimento necessário das circunstâncias particulares de cada ocorrência. Adicionalmente, embora a importância relativa do gado na dieta da onça-pintada ou da onça-parda possa ser determinada através da análise de fezes, cabe lembrar que essa técnica não permite a determinação da causa da morte do animal consumido. Por esse motivo, é fundamental que sejam consideradas todas as variáveis possíveis, ao se estabelecer o papel da onça como predador no consumo do gado, na formação dos conceitos e opiniões de fazendeiros e peões, pois essas informações interferem diretamente nas decisões que determinam a conservação das onças em uma região. Esse fato é tanto mais relevante quando se considera o peso que assumem os exemplos de pares (ou de outros fazendeiros), nas atitudes positivas ou negativas entre propriedades vizinhas.

\section{DIMENSÕES HUMANAS}

Uma premissa central na conservação de predadores de grande porte é a de que a perseguição a esses animais está diretamente relacionada ao dano econômico que causam ao matar animais domésticos (Redpath et al., 2013; Marchini \& Crawshaw Jr., 2015). Isso se aplica também ao conflito envolvendo onças-pintadas no Pantanal (Azevedo \& Murray, 2007b). Decorre dessa premissa, então, que para se prevenir a perseguição aos predadores basta evitar o dano econômico da depredação, seja impedindo o ataque do predador sobre animais domésticos, seja compensando monetariamente o produtor pelo dano causado pelo predador. Em outras palavras, ecologia e economia poderiam, juntas, proporcionar a base necessária para o manejo e a resolução do problema.

No entanto, é crescente a evidência de que o dano causado pelas onças não é o único fator que explica a perseguição a esses animais, e talvez nem seja o mais importante (Marchini \& Macdonald, 2018). Isso ocorre por duas razões: 1) pode haver discrepância considerável entre o dano real e o dano percebido. O que determina o comportamento humano (nesse caso, o de perseguir e matar as onças) não é a realidade em si, mas sim, como a realidade é percebida. Em conflitos envolvendo espécies carismáticas e polêmicas como as onças, risco e dano percebidos geralmente excedem as evidências (Conover, 2002; Marchini \& Macdonald, 2012). Reforço mútuo entre notoriedade e sensacionalismo pode estar por trás

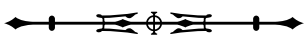


das percepções distorcidas. Por exemplo, Marchini (2010) demonstrou que ataques de onças sobre seres humanos têm lugar de destaque ao serem divulgados ('causos') em comunidades rurais do Brasil, incluindo o Pantanal, e a teoria sugere que, ao serem contados repetidamente, esses relatos podem reforçar a própria plausibilidade e importância (Kuran \& Sunstein, 1999); 2) fatores que não estão diretamente relacionados à depredação de animais domésticos pelas onças também podem estar envolvidos na perseguição (Knox et al., 2019). Por exemplo, predadores de grande porte, como as onças, despertam emoções negativas fortes, principalmente medo (Manfredo, 2008), e as pessoas que têm mais medo de predadores geralmente são menos tolerantes a eles (Roskaft et al., 2007). É provável que esse medo tenha evoluído como uma resposta antipredador e possa ser exagerado à luz dos fatos; por exemplo, Marchini \& Macdonald (2012) mostraram que o medo é um fator determinante no abate de onças na fronteira de desmatamento da Amazônia, no norte de Mato Grosso, embora registros de ataques de onças a humanos na região sejam quase inexistentes. A perseguição às onças pode resultar também de motivações sociais. Os resultados de Marchini (2010) revelaram que motivações sociais são também determinantes importantes na intenção de matar onças no Pantanal, onde 25\% dos produtores justificaram sua aprovação ao abate de onças com base na tradição cultural. Esses produtores geralmente se referem, com evidente orgulho, à 'cultura pantaneira' e à convicção de que a caça à onça tem sido passada de geração a geração como um elemento natural daquela cultura. Exemplo disso é o fato de que, mesmo em fazendas em que o proprietário proíbe que onças sejam mortas, os empregados as matam quando têm oportunidade, ainda que corram o risco de perder o emprego, se descobertos. Dickman et al. (2013) discutem como outros fatores em nível individual (como experiência, habilidades específicas, conhecimentos, valores) e sociocultural (por exemplo, fonte de renda, folclore e religião) afetam o comportamento humano em relação à fauna silvestre, podendo justificar a sua perseguição.
Além do abate de onças-pintadas e das suas diversas causas pessoais e socioculturais, conservacionistas e gestores de vida silvestre devem estar atentos também ao potencial que espécies carismáticas e polêmicas, tais como as onças, pardas e pintadas, têm de provocar conflito de interesses entre diferentes grupos sociais. De fato, o termo 'conflito humano-fauna silvestre' - e, mais especificamente, o termo 'conflito humano-onças' - tem sido usado para se referir a duas situações diferentes: uma em que a fauna silvestre causa dano - no caso das onças, ferindo ou matando animais domésticos - e outra em que grupos de pessoas divergem sobre objetivos ou alternativas referentes ao manejo da fauna silvestre. A primeira situação é, em última análise, um fenômeno ecológico, já que a disputa entre humanos e onças por recursos (como o gado) pode ser entendida dentro do marco conceitual bem estabelecido da teoria da competição em ecologia de comunidades.

'Conflito', por outro lado, não pertence ao glossário de termos ecológicos. A segunda situação é a de verdadeiro conflito em conservação, definido como "uma situação que ocorre quando duas ou mais partes com opiniões fortes divergem sobre objetivos de conservação e manejo e quando uma parte é percebida como impondo seus interesses a custo da outra" (Redpath et al., 2013, p. 100). Essa definição reconhece que conflitos em conservação ocorrem fundamentalmente entre humanos. As duas situações são relacionadas e podem acontecer ao mesmo tempo, mas tratá-las indistintamente, sob a denominação de 'conflito humano-fauna silvestre', pode simplificar demais a maneira como os problemas são definidos e limitar o leque de soluções potenciais disponíveis. Os métodos usados para resolver problemas de danos causados pelas onças - soluções técnicas e mitigatórias, tais como controle letal, translocação, uso de cercas, repelentes e compensação financeira - por exemplo, diferem das soluções para os conflitos sociais em torno da espécie, estas geralmente mais desafiadoras.

Embora conflitos sociais possam ser causados simplesmente pelo dano material - quando este ocorre 
de forma desigual e os grupos sociais mais gravemente afetados demandam medidas mais rígidas contra a fauna do que os grupos menos afetados -, eles geralmente são baseados também em fatores subjetivos. As pessoas podem discordar em relação a objetivos e medidas alternativas de manejo da onça-pintada no Pantanal por razões afetivas, estéticas ou éticas, por exemplo. Nenhuma outra espécie da fauna brasileira desperta emoções positivas (como admiração) e negativas (como medo e raiva) simultaneamente e com tanta força quanto a onça-pintada (Marchini, 2010). Esses sentimentos, porém, variam significativamente com gênero, idade, escolaridade (Marchini, 2010) e ramo de atividade (i.e. pecuária, pesca, turismo; Marchini, 2003) das pessoas consultadas. Amâncio et al. (2015) discutiram as diferentes visões de moradores ribeirinhos, peões de fazenda e proprietários sobre a onça-pintada no Pantanal e concluíram que a conservação da espécie só será possível através do manejo sustentável das fazendas e da compreensão da dimensão humana, na convivência entre o homem e a onça-pintada. Conforme os autores, essa conclusão é particularmente relevante no Pantanal, onde, diferentemente de outros ecossistemas mais ameaçados, a conservação da onça-pintada depende mais do manejo de áreas privadas, na forma de grandes fazendas, do que de Unidades de Conservação (UC), que são pouco representadas naquele bioma. Uma dificuldade é que, enquanto nas UC o número de atores é reduzido, em propriedades privadas os atores são múltiplos e com representações e interesses heterogêneos quanto à convivência com as onças. Entender e envolver esses atores são aspectos fundamentais para a conservação e o manejo da onça-pintada na região.

Além disso, a fauna silvestre, muitas vezes, torna-se álibi para rixas profundamente arraigadas dentro ou entre grupos culturalmente distintos, notadamente quando a divisão urbano-rural está envolvida. A urbanização, com o afastamento das pessoas do convívio com a fauna, gera um ativismo em benefício da fauna silvestre. No entanto, os custos imediatos da convivência com a fauna silvestre recorrem (ou são percebidos como recorrentes) sobre as populações rurais (Swenson \& Andrén, 2005). Produtores rurais são uma minoria em declínio no Brasil e, como resultado, podem associar a conservação da vida silvestre com os valores antagonistas urbanos que lhes vêm sendo impostos de forma crescente, podendo considerar a continuidade da caça - o abate de onças, por exemplo como parte de sua resistência e da luta para preservar a própria herança cultural rural (Marchini, 2010).

Em suma, a negatividade em relação à onça-pintada não é determinada meramente por qualquer custo direto decorrente da depredação, mas é produto de uma trama dinâmica e complexa de fatores individuais (como a percepção de risco e medo), sociais (incluindo pressão dos pares, glamour e conflito social) e culturais (como manter a identidade de um grupo em particular). É preciso entender melhor a relação entre o dano real causado pelas onças e o seu abate, para que a eficácia de muitas das ações de conservação e mitigação baseadas estritamente na ecologia e economia da depredação de animais domésticos - não seja comprometida.

Assim, como apontado há 35 anos por Crawshaw Jr. e Quigley (1984), vários estudos recentes têm confirmado a importância de aspectos individuais, sociais e culturais na elaboração de estratégias mais efetivas de conservação das onças no Pantanal (Amâncio et al., 2015; Cavalcanti \& Gese, 2010; Cavalcanti et al., 2010; Marchini \& Macdonald, 2012). Cavalcanti et al. (2010) enfatizaram a importância de dados quantitativos coletados em campo para desmistificar crenças errôneas sobre o impacto da predação, bem como ressaltaram o valor de usar essas informações para diminuir a probabilidade dessa predação e enfraquecer a justificativa do prejuízo econômico (Cavalcanti et al., 2012). No entanto, talvez ainda mais importante seja chegar ao 'inconsciente coletivo' sociocultural de cada comunidade que convive com esses predadores, de forma a interferir de maneira positiva na impressão formada sobre a espécie, evitando, assim, que os animais sejam desnecessariamente mortos.

Aparentemente, uma das melhores formas de se chegar a isso é através das crianças e da escola, cujos 
efeitos têm maior influência em mudanças de atitudes dos pais, em comunidades rurais (Marchini \& Macdonald, 2020). Esse efeito já havia sido verificado em um projeto de educação ambiental implantado em escolas nas imediações do Parque Nacional do Iguaçu, na década de 90 (Manzatti, 1994, 1999). No entanto, uma avaliação subjetiva dos trabalhos nesse projeto, passados mais de 20 anos, sugere que essa relação crianças-pais-professores-comunidadeconservacionistas tenha que ser continuamente trabalhada, pois os efeitos positivos tendem a se diluir e se abrandar com o passar dos anos, com consequências negativas em programas de conservação dos predadores, principalmente considerando populações ameaçadas.

\section{CONCLUSÃO}

Conforme sugerido por Amâncio et al. (2015), considerando a recuperação das populações de onças em algumas áreas do Pantanal e o seu importante papel ecológico no ecossistema pantaneiro, é necessário reconhecer a predação por grandes felinos como uma característica inerente à criação de gado, da mesma forma que os processos naturais de cheia e seca, doenças, acidentes com outras espécies, perdas devido ao transporte e manejo do gado, animais atolados, entre outros. Os resultados aqui discutidos enfatizam alguns aspectos ecológicos importantes sobre o comportamento da onça-pintada e seu hábito predatório sobre o gado no Pantanal (Azevedo \& Murray, 2007a; Cavalcanti, 2008) e ilustram sua natureza oportunista, pela qual a espécie parece tirar vantagem de um ambiente em constante mudança e no qual os recursos alimentares variam tanto no tempo quanto no espaço (Cavalcanti \& Gese, 2010).

Devido à essa natureza oportunista como predador, onças-pintadas eventualmente irão atacar animais domésticos, mesmo que uma base regular de presas nativas esteja disponível. Por esse motivo, é importante identificar técnicas e alternativas de manejo que dificultem o acesso dos animais domésticos a esses predadores, como os relatados por Cavalcanti et al. (2012) e Tortato et al. (2015). Em alguns casos, talvez seja necessário usar métodos combinados ou alternados, como cercas elétricas, iluminação, sons e fogos de artifício, evitando que o animal aprenda a reconhecer falhas no uso ou na repetição de um mesmo tipo de sistema (Cavalcanti, 2006; Marchini et al., 2011), familiarizando-se com determinado método e, consequentemente, diminuindo sua eficácia. Em outros casos, ao invés de se 'combater o inimigo', talvez seja possível usar o carisma dessas espécies como uma vantagem econômica, usando-os como atrativos turísticos, conforme mostrado com sucesso em vários empreendimentos no Pantanal, que combinam a pecuária com o atendimento a hóspedes, em hotéis e pousadas ecológicas (Tortato et al., 2017; Tortato \& Izzo, 2017).

Em relação às medidas alternativas para reduzir a predação, Cavalcanti et al. (2012) mostraram resultados indicando que ela foi reduzida quando da transferência do gado para pastagens abertas de boa visibilidade, onde a aproximação de um predador era mais facilmente detectada. Em locais onde o gado ficava confinado à vegetação mais alta, a predação aumentava consideravelmente. $\bigcirc$ patrulhamento noturno, feito por meio de um trator em um corredor central entre pastagens onde o gado era mantido à noite, foi também efetivo para reduzir a predação, quando ocorria à noite. Dependendo da situação em particular, cercas elétricas podem ser eficientes para deter alguns predadores, em tentativas de predação de animais domésticos. Fogos de artifício e iluminação noturna, conforme utilizado na fazenda de estudo, de forma repetitiva e sem estar necessariamente associados à presença efetiva de uma onça, tiveram pouco efeito nos resultados da predação.

Os resultados do referido estudo enfatizaram alguns dos problemas associados ao uso inadequado de cercas elétricas e de outros métodos alternativos para diminuir a predação de animais domésticos por grandes felinos no Pantanal. Apesar da resistência ao uso de cercas elétricas para a conservação em alguns países (Hayward et al., 2008), o seu uso de maneira adequada pode ajudar a reduzir o conflito entre grandes felinos 
e produtores rurais. No entanto, é importante compreender que raramente existe uma única forma 'correta' de prevenir ou resolver o problema de depredação de animais domésticos. A eficácia de qualquer método irá depender de uma combinação de fatores que inclui a biologia do predador e a sua motivação, as características ambientais da área, o tamanho e espécie doméstica a ser considerada, os fatores culturais da população local, e a motivação do proprietário da fazenda, bem como sua disposição para solucionar o problema.

Outra forma para diminuir o prejuízo, portanto, é concentrar esforços em aumentar a produção, diminuindo perdas devido ao manejo rudimentar e técnicas reprodutivas pouco eficazes, as quais podem ser mais significativas do que a predação em si (Hoogesteïn et al., 1993). Além disso, Cavalcanti \& Gese (2010) ilustraram os efeitos potenciais da abundância de presas nativas sobre a depredação de onças-pintadas em relação ao gado. A manutenção de populações saudáveis de presas silvestres em fazendas no Pantanal aparentemente não apenas ajuda a diminuir as perdas na predação do gado, como é um importante fator para a conservação da onça-pintada, em longo prazo.

As características inerentes do Pantanal tornam difícil o controle de acesso dos predadores ao gado. Desta forma, é muito provável que a predação continue ocorrendo, em maior ou menor grau. No presente artigo, são apresentadas informações novas e complementares sobre a dinâmica da predação do gado pela onçapintada no Pantanal e sua relação com fatores climáticos e características da hidrologia, vegetação e com a fauna nativa. Somada àquelas disponíveis na literatura, é cada vez mais possível uma melhor compreensão sobre o tema e, consequentemente, um melhor planejamento e aplicação de medidas mais eficientes para diminuir o impacto econômico que a predação representa na região. No entanto, acima de tudo, é preciso uma abordagem integrada no que diz respeito à conservação no Pantanal, que inclua as dimensões humanas (aspectos pessoais, sociais e culturais) nas fases de diagnóstico, intervenção e monitoramento de resultados, abrangência geográfica adequada, envolvimento dos atores, embasamento adequado na legislação vigente, porém coerente com a realidade local, e, finalmente, um programa de monitoramento em longo prazo das populações de grandes predadores.

\section{REFERÊNCIAS}

Abreu, U. G. P., Santos, S. A., Barros, L. F., \& Domingos, I. T. (2008). Pecuária de corte e a conservação do Pantanal. EMBRAPA Pantanal.

Almeida, A. (1976). Jaguar hunting in Mato Grosso. Stanwill Press.

Amâncio, C. G., Crawshaw Jr., P. G., Tomás, W. M., Rodrigues, R. B., \& Vergara da Silva, M. (2015). A dimensão humana e sua influência na conservação de carnívoros no Brasil: o exemplo do Pantanal. In S. M. C. Cavalcanti, R. C. de Paula \& R. L. Gasparini-Morato (Eds.), Conflito com mamíferos carnívoros: uma referência para o manejo e a convivência (pp. 101-108). ICMBio/CENAP.

Azevedo, F. C. C., \& Murray, D. L. (2007a). Spatial organization and food habits of jaguars (Panthera onca) in a floodplain forest. Biological Conservation, 137(3), 391-402. https://doi. org/10.1016/j.biocon.2007.02.022

Azevedo, F. C. C., \& Murray, D. L. (2007b). Evaluation of potential factors predisposing livestock to predation by jaguars. Journal of Wildlife Management, 71(7), 2379-2386. https://doi. org/10.2193/2006-520

Bourscheit, A. (2013). Código Florestal completa um ano com poucos avanços. Notícias, WWF Brasil. http://www.wwf. org.br/?34982/Codigo-Florestal-completa-um-ano-compoucos-avanços

Bragança, D. (2013). Projeto libera mineração em parques e de quebra muda SNUC. Reportagens, O Eco. https://oeco.org. br/reportagens/27801-projeto-libera-mineracao-em-parquese-de-quebra-muda-snuc/

Camilo, A. R. (2012). Distribuição potencial de onça-parda (Puma concolor) e onça-pintada (Panthera onca) no Pantanal brasileiro [Dissertação de Mestrado, Universidade Federal de Mato Grosso do Sul, Campo Grande].

Catto, J. B., Bianchin, I., \& Torres Jr., R. A. A. (2005). Efeitos da everminação de matrizes e de bezerros lactentes em sistema de produção de bovinos de corte na região de Cerrado. Pesquisa Veterinária Brasileira, 25(3), 188-194. https://doi. org/10.1590/S0100-736X2005000300010

Cavalcanti, S. M. C. (2006). Identificação e controle de danos causados por espécies da fauna silvestre. In L. Cullen, R. Rudran \& C. V. Pádua (Eds.), Métodos de estudos em biologia da conservação e manejo da vida silvestre (pp. 203-242). Smithsonian Institution/Instituto de Pesquisas Ecológicas.

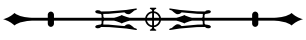


Cavalcanti, S. M. C. (2008). Predator-prey relationships and spatial ecology of jaguars in the southern Pantanal, Brazil: implications for conservation and management [Tese de doutorado, Utah State University]. https://doi.org/10.26076/dc41-1ba6

Cavalcanti, S. M. C. (2009). Pantanal Jaguar Project - Northern Corridor. Activity Report, November 2008 - January 2009. Panthera.

Cavalcanti, S. M. C., \& Gese, E. M. (2009). Spatial ecology and social interactions of jaguars (Panhtera onca) in the Southern Pantanal, Brazil. Journal of Mammalogy, 90(4), 935-945. https:// doi.org/10.1644/08-MAMM-A-188.1

Cavalcanti, S. M. C. (2010). Análise crítica do programa de gestão de conflitos e do banco de dados de predação. ICMBio/CENAP.

Cavalcanti, S. M. C., \& Gese, E. M. (2010). Kill rates and predation patterns of jaguars (Panthera onca) in the southern Pantanal, Brazil. Journal of Mammalogy, 91(3), 722-736. http://dx.doi. org/10.1644/09-MAMM-A-171.1

Cavalcanti, S. M. C., Marchini, S., Zimmermann, A., Gese, E. M., \& Macdonald, D. W. (2010). Jaguars, livestock and people in Brazil: reality and perceptions behind the conflict. In D. W. Macdonald \& A. J. Loveridge (Eds.), Biology and conservation of wild felids (pp. 383-402). Oxford University Press.

Cavalcanti, S. M. C., Crawshaw Jr., P. G., \& Tortato, F. R. (2012). Use of electric fencing and associated measures as deterrents to jaguar predation on cattle in the Pantanal of Brazil. InM. J. Somers \& M. W. Hayward (Ed.), Fencing for conservation: restriction of evolutionary potential or a riposte to threatening processes? (pp. 295-309). Springer.

Conover, M. R. (2002). Resolving human-wildife conflicts: the science of wildlife damage management. Lewis Publishers.

Crawshaw Jr., P. G., \& Quigley, H. B. (1984). Ecologia do jaguar ou onça-pintada no Pantanal. Instituto Brasileiro de Desenvolvimento Florestal.

Crawshaw Jr., P. G. (2002). Mortalidad inducida por humanos y la conservación de jaguares: el Pantanal y el Parque Nacional Iguaçu en Brasil. In R. A. Medellin, C. Chetkiewicz, P. G. Crawshaw Jr., A. Rabinowitz, K. H. Redford, J. G. Robinson, E. Sanderson \& A. Taber (Eds.), Jaguars in the new millennium: A status assessment, priority detection, and recommendations for the conservation of jaguars in the Americas (pp. 451-464). Universidad Nacional Autónoma de México/Wildlife Conservation Society.

Crawshaw Jr., P. G., \& Quigley, H. B. (2002). Hábitos alimenticios del jaguar y el puma en el Pantanal, Brasil, con implicaciones para su manejo y conservación. In R. A. Medellin, C. Equihua, C. L. B. Chetkiewicz, P. G. Crawshaw Jr., A. Rabinowitz, K. H. Redford, . . . \& A. Taber (Eds.), El jaguar en el nuevo milenio: A status assessment, priority detection, and recommendations for the conservation of jaguars in the America (pp. 223235). Universidad Nacional Autónoma de México/Wildlife Conservation Society.
Crawshaw Jr., P. G. (2003). Uma perspectiva sobre a depredação de animais domésticos por grandes felinos no Brasil. Natureza \& Conservação, 1(1), 13-15.

Crawshaw Jr., P. G., Mahler, J. K., Indrusiak, C., Cavalcanti, S. M. C., Leite, M. R. P., \& Silvius, K. (2004). Ecology and conservation of jaguar (Panthera onca) in Iguaçu National Park, Brazil. In K. M. Silvius, R. E. Bodmer \& J. M. V. Fragoso (Eds.), People in nature: wildlife conservation in South and Central America (pp. 271-285). Columbia University Press.

Crawshaw Jr., P. G., Tomás, W, \& Lima, R. P. (2008). O cerco se fecha sobre o Pantanal. O(eco). https://oeco.org.br/colunas/20064o-cerco-se-fecha-sobre-o-pantanal/

Dalponte, J. C. (2002). Dieta del jaguar y depredación de ganado en el norte del Pantanal, Brasil. In R. A. Medellin, C. Equihua, C. L. B. Chetkiewicz, P. G. Crawshaw Jr., A. Rabinowitz, K. H. Redford, ... \& A. Taber (Eds.), El jaguar en el nuevo milenio: A status assessment, priority detection, and recommendations for the conservation of jaguars in the America (pp. 209-221). Universidad Nacional Autónoma de México/Wildlife Conservation Society.

De La Torre, J. A., González-Maya, J. F., Zarza, H. E., Ceballos, G., \& Medellín, R. A. (2017). The jaguar's spots are darker than they appear: assessing the global conservation status of the jaguar Panthera onca. Oryx, 52(2), 300-315. https://doi. org/10.1017/S0030605316001046

De Paula, T. A., \& Silva Neto, P. B. (2006). Criação racional de capivaras (Hydrochoerus hydrochaeris). In M. A. Rotta, H. S. Luna \& W. A. Weis (Eds.), Ecoturismo no Pantanal (pp. 107122). EMBRAPA Pantanal.

Desbiez, A. L. J., Bodmer, R. E., \& Tomas, W. M. (2010). Mammalian densities in a neotropical wetland subject to extreme climatic events. Biotropica, 42(3), 372-378. https://doi.org/10.1111/ j.1744-7429.2009.00601.x

Desbiez, A. L. J., Keroughlian, A., Piovezan, U., \& Bodmer, R. E. (2011). Invasive species and bushmeat hunting contributing to wildlife conservation: the case of feral pigs in a Neotropical wetland. Oryx, 45(1), 78-83. https://doi.org/10.1017/ S0030605310001304

Dickman, A. J., Marchini, S., \& Manfredo, M. (2013). The importance of the human dimension in addressing conflict with large carnivores. In D. W. Macdonald \& K. J. Willis (Eds.), Key topics in conservation biology (vol. 2, pp. 110-126). Wiley-Blackwell.

Duarte, J. M. B. (1996). Guia de identificação dos cervídeos brasileiros. FUNEP.

Ewer, R. F. (1968). Ethology of mammals. Logos Press.

Ewer, R. F. (1973). The carnivores. Cornell University Press.

Farrell, L. E. (1999). The ecology of the puma and the jaguar in the Venezuelan Llanos [Tese de Doutorado, University of Florida].

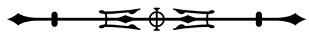


Fox, J., \& Chundawat, R. (1988). Observations of snow leopard stalking, killing, and feeding behavior. Mammalia, 52(1), 137140.

Harris, M. B., Tomas, W., Mourão, G., Silva, C. J., Guimarães, E., Sonoda, F., \& Fachim, E. (2005). Safeguarding the Pantanal wetlands: threats and conservation initiatives. Conservation Biology, 19(3), 714-720.

Hayward, M. W., Hayward, G. J., Druce, D., \& Kerley, G. I. H. (2008). Do fences constrain predator movements on an evolutionary scale? Home range, food intake and movement patterns of large predators reintroduced to Addo Elephant National Park, South Africa. Biodiversity and Conservation, 18(4), 887-904. https://doi.org/10.1007/s10531-008-9452-y

Hoogesteijn, R., \& Mondolfi, E. (1992). The jaguar. Armitano Publishers.

Hoogesteijn, R., Hoogesteijn, A., \& Mondolfi, E. (1993). Jaguar predation vs. conservation: cattle mortality caused by felines on three ranches in the Venezuelan Llanos. Symposium of the Zoological Society of London, 65, 391-407.

Jorgenson, J. P., \& Redford, K. H. (1993). Humans and big cats as predators in the Neotropics. Symposium of the Zoological Society of London, 65, 367-390.

Kitchener, A. (1991). The natural history of the wild cats. Cornell University Press.

Knox, J., Negrões, N., Marchini, S., Barboza, K., Guanacoma, G., Balhau, P., . . . \& Glikman, J. A. (2019). Jaguar persecution without "cowflict": insights from protected territories in the Bolivian Amazon. Frontiers in Ecology and Evolution, 7, 494. https://doi.org/10.3389/fevo.2019.00494

Kuran, T., \& Sunstein, C. R. (1999). Availability cascades and risk regulation. Stanford Law Review, 51(4), 123-134. https://doi. org/10.2307/1229439

Linnell, J. D. C., Odden, J., Smith, M. E., Aanes, R., \& Swenson, J. E. (1999). Large carnivores that kill livestock: do problem individuals exist? Wildlife Society Bulletin, 27(3), 698-705.

Logan, K. A., \& Sweanor, L. L. (2001). Desert puma: evolutionary ecology and conservation of an enduring carnivore. Island Press.

Lopez-Gonzales, C. A., \& Piña, G. L. (2002). Carrion use by jaguars (Panthera onca) in Sonora, Mexico. Mammalia, 66(4), 603-605.

Lourival, F. F. R., \& Fonseca, G. A. B. (1997). Análise da sustentabilidade do modelo de caça tradicional, no Pantanal da Nhecolândia, Corumbá, MS. In C. V. Pádua \& R. E. Bodmer (Eds.), Manejo e conservação de vida silvestre no Brasil (pp. 123-172). Sociedade Civil Mamirauá.

Manfredo, M. J. (2008). Who cares about wildlife? Springer.
Manzatti, L. (1994). Educação ambiental do Projeto "Carnívoros do Parque Nacional do Iguaçu". Fundação O Boticário de Proteção à Natureza/Instituto Brasileiro do Meio Ambiente e dos Recursos Naturais Renováveis.

Manzatti, L. (1999). Predação de animais domésticos e plantações no entorno do Parque Nacional do Iguaçu (PR) - Análise da percepção de fazendeiros e alternativas de manejo [Dissertação de Mestrado, ESALQ/USP].

Marchini, S. (2003). Pantanal: opinião pública local sobre meio ambiente e desenvolvimento. Instituto de Desenvolvimento Sustentável Mamirauá.

Marchini, S. (2010). Human dimensions of the conflicts between people and jaguars (Panthera onca) in Brazil [Tese de doutorado, University of Oxford].

Marchini, S., Cavalcanti, S. M. C., \& de Paula, R. C. (2011) Predadores silvestres e animais domésticos - guia prático de convivência. Instituto Chico Mendes de Conservação da Biodiversidade.

Marchini, S., \& Macdonald, D. W. (2012). Predicting ranchers' intention to kill jaguars: case studies in Amazonia and Pantanal. Biological Conservation, 147(1), 213-221. https: //doi. org/10.1016/j.biocon.2012.01.002

Marchini, S., \& Crawshaw Jr., P. G. (2015). Human-wildlife conflicts in Brazil: a fast-growing issue. Human Dimensions of Wildlife, 20(4), 323-328. https://doi.org/10.1080/10871209.2015.10 04145

Marchini, S., \& Macdonald, D. W. (2018). Mind over matter: perceptions behind the impact of jaguars on human livelihoods. Biological Conservation, 224, 230-237. https://doi. org/10.1016/j.biocon.2018.06.001

Marchini, S., \& Macdonald, D. W. (2020). Can school children influence adults' behavior toward jaguars? Evidence of intergenerational learning in education for conservation. Ambio, 49, 912-925. https://doi.org/10.1007/s13280-01901230-w

Michalski, F., Boulhosa, R. L. P., Faria, A., \& Peres, C. A. (2006). Human-wildlife conflicts in a fragmented Amazonian forest landscape: determinants of large felid depredation on livestock. Animal Conservation, 9(2), 179-188. http://dx.doi. org/10.1111/j.1469-1795.2006.00025.x

Mourão, G. M., Coutinho, M. E., Mauro, R. A., Tomas, W. M., \& Magnusson, W. (2002). Levantamento aéreos de espécies introduzidas no Pantanal: porcos ferais (porco monteiro), gado bovino e búfalos (Boletim de Pesquisa e Desenvolvimento, 28). EMBRAPA Pantanal.

Møller, A. P., \& Erritzøe, J. (2014). Predator-prey interactions, flight initiation distance and brain size. Journal of Evolutionary Biology, 2(7), 34-42. http://dx.doi.org/10.1111/jeb.12272 
Noss, R. F. (1995). Maintaining ecological integrity in representative reserve networks. World Wildlife Fund.

Nowak, R. M. (1999). Walker's mammals of the world. John Hopkins University Press.

Nowell, K., \& Jackson, P. (1996). Wild cats: status survey and conservation action plan. IUCN/SSC Cat Specialist Group.

Perilli, M. L. L. (2010). Ecologia alimentar da onça-pintada (Panthera onca) na região sul do Pantanal utilizando análise de fezes - uma comparação com o método direto de rádio-telemetria GPS [Dissertação de mestrado, Universidade Federal do Mato Grosso do Sul]. http://www.dominiopublico.gov.br/pesquisa/ DetalheObraForm.do?select_action $=\&$ co_obra $=176257$

Perilli, M. L. L, Lima, F., Rodrigues, F. H. G, \& Cavalcanti, S. M. C. (2016). Can scat analysis describe the feeding habits of big cats? A case study with jaguars (Panthera onca) in southern Pantanal, Brazil. PloS ONE, 11(3), 1-12. https://doi.org/10.1371/ journal.pone.0151814

Perovic, P. G. (2002). Conservación del jaguar en el noroeste de Argentina. In R. A. Medellin, C. Equihua, C. L. B. Chetkiewicz, P. G. Crawshaw Jr., A. Rabinowitz, K. H. Redford, . . . \& A. Taber (Eds.), El jaguar en el nuevo milenio: A status assessment, priority detection, and recommendations for the conservation of jaguars in the America (pp. 465475). Universidad Nacional Autónoma de MéxicoMildlife Conservation Society.

Polisar, J., Maxit, I., Scognamillo, D., Farrell, L., Sunquist, M., \& Eisenberg J. (2003). Jaguars, pumas, their prey base, and cattle ranching: ecological interpretations of a management problem. Biological Conservation, 109(2), 297-310. http://doi. org/10.1016/S0006-3207(02)00157-X

Porfírio, G. E. O. (2009). Ecologia alimentar da onça-pintada (Panthera onca) na sub-região do Pantanal de Miranda, MS, Brasil [Dissertação de mestrado, Universidade Federal de Mato Grosso do Sul]. https://repositorio.ufms.br/ handle/123456789/577

Prance, G. T., \& Schaller, G. B. (1982). Preliminary study of some vegetation types of the Pantanal, Mato Grosso, Brazil. Brittonia, 34, 228-251. https://doi.org/10.2307/2806383

Quammen, D. (2005). Monster of God. Random House.

Quigley, H. B. (1987). Ecology and conservation of the jaguar in the Pantanal region, Mato Grosso do Sul, Brazil [Tese de Doutorado, University of Idaho].

Rabinowitz, A. R. (1986). Jaguar predation on domestic livestock in Belize. Wildlife Society Bulletin, 14(2), 170-174.

Ray, J. C., Redford, K. H., Steneck, R. S., \& Berger, J. (2005). Large carnivores and the conservation of biodiversity. Island Press.
Redpath, S. M., Young, J., Evely, A., Adams, W. M., Sutherland, W. J., Whitehouse, A., . . \& Gutierrez, R. J. (2013). Understanding and managing conservation conflicts. Trends in Ecology \& Evolution, 28(2), 100-109. http://doi.org/10.1016/j.tree.2012.08.021

Ricklefs, R. E., \& Miller, G. (2000). Ecology. W. H. Freeman.

Rodrigues, F. H. G., Medri, I. M., Tomas, W. M., \& Mourão, G. M. (2002). Revisão do conhecimento sobre ocorrência e distribuição de mamíferos do Pantanal. EMBRAPA Pantanal.

Roosevelt, T. (1914). Through the Brazilian wilderness. C. Scribner's Sons.

Roskaft, E., Handel, B., Bjerke, T., \& Kaltenborn, B. P. (2007). Human attitudes towards large carnivores in Norway. Wildlife Biology, 13, 172-185. https://doi.org/10.2981/09096396(2007)13[172:HATLCI]2.0.CO;2

Sáenz, J. C., \& Carrillo, E. (2002). Jaguares depredadores de ganado en Costa Rica: iun problema sin solución? In R. A. Medellin, C. Equihua, C. L. B. Chetkiewicz, P. G. Crawshaw Jr., A. Rabinowitz, K. H. Redford . . . \& A. Taber (Eds.), El jaguar en el nuevo milenio: A status assessment, priority detection, and recommendations for the conservation of jaguars in the America (pp. 127-137). Universidad Nacional Autónoma de México/ Wildlife Conservation Society.

Sanderson, E. W., Redford, K. H., Chetkiewicz, C. B., Medellin, R. A., Rabinowitz, A. R., Robinson, J. G., \& Taber A. B. (2002). Planning to save a species: the jaguar as a model. Conservation Biology, 16(1), 58-72. http://doi.org/10.1046/.1523-1739.2002.00352.X

Schaller, G. B. (1983). Mammals and their biomass in a Brazilian ranch. Arquivos de Zoologia, 31(1), 1-36. https://doi.org/10.11606/ issn.2176-7793.v31i1p1-36

Schaller, G. B. (2012). Tibet wild: A naturalist's journey to the roof of the world. Island Press.

Schaller, G. B., \& Crawshaw Jr., P. G. (1980). Movement patterns of jaguar. Biotropica, 12(3), 161-168. https://doi. org/10.2307/2387967

Scognamillo, D., Maxit, I. E., Sunquist, M., \& Farrell, L. (2002). Ecologia del jaguar y el problema de la depredacion sobre ganado en Hato Piñero, Venezuela. In R. A. Medellin, C. Equihua, C. L. B. Chetkiewicz, P. G. Crawshaw Jr., A. Rabinowitz, K. H. Redford, . . . \& A. Taber (Eds.), El jaguar en el nuevo milenio: A status assessment, priority detection, and recommendations for the conservation of jaguars in the America (pp. 139-150). Universidad Nacional Autónoma de México/ Wildlife Conservation Society.

Soisalo, M. K., \& Cavalcanti, S. M. C. (2006). Estimating the density of a jaguar population in the Brazilian Pantanal using cameratraps and capture-recapture sampling in combination with GPS radio-telemetry. Biological Conservation, 129(4), 487-496. https://doi.org/10.1016/j.biocon.2005.11.023 
Specht, L., Quadros, S. A. F., Erpen, J. G., \& Rosa, A. C. M. (2012). Avaliação da sustentabilidade da pecuária de corte extensiva tradicional do Pantanal Sul-Mato-Grossense através da metodologia eMergética. Revista Brasieira de Agroecologia, 7(3), 1625. https://orgprints.org//d/eprint/22788/1/12794-54109-1-PB.pdf

Stander, P. E. (1990). A suggested management strategy for stock-raiding lions in Namibia. South African Journal of Wildlife Research, 20(2), 37-43. https://hdl.handle.net/10520/AJA03794369_3323

Stolzenberg, W. (2008). Where the wild things were. Bloomsbury.

Sunquist, M. E., \& Sunquist, F. C. (1989). Ecological constraints on predation by large felids. In J. L. Gittleman (Ed.), Carnivore behavior, ecology, and evolution (pp. 283-301). Comstock Publishing Associates.

Swenson, J. E., \& Andrén, H. (2005). A tale of two countries: large carnivore depredation and compensation schemes in Sweden and Norway. In R. Woodroffe, S. Thirgood \& A. Rabinowitz (Eds.), People and wildlife: conflict or coexistence? (pp. 323339). Cambridge University Press.
Tortato, F. R., Layme, V. M. G., Crawshaw Jr., P. G., \& Izzo, T. J. (2015). The impact of herd composition and foraging area on livestock predation by big cats in the Pantanal of Brazil. Animal Conservation, 18(6), 539-547. https://doi.org/10.1111/acv.12207

Tortato, F. R., Izzo, T. J., Hoogesteijn, R., \& Peres, C. A. (2017). The numbers of the beast: Valuation of jaguar (Panthera onca) tourism and cattle depredation in the Brazilian Pantanal. Global Ecology and Conservation, 11, 106-114. https://doi.org/10.1016/j. gecco.2017.05.003

Tortato, F. R., \& Izzo, T. J. (2017). Advances and barriers to the development of jaguar-tourism in the Brazilian Pantanal. Perspectives in Ecology and Conservation, 15, 61-63. https://doi. org/10.1016/j.pecon.2017.02.003

\section{CONTRIBUIÇÃO DOS AUTORES}

S. M. C. Cavalcanti contribuiu com conceituação, investigação, escrita do rascunho original, revisão e edição de versões recentes do manuscrito; P. G. Crawshaw Jr. com conceituação, investigação e escrita do rascunho original; e S. Marchini com conceituação, investigação, escrita do rascunho original, revisão e edição de versões recentes do manuscrito. 